Florida International University FIU Digital Commons

$11-2-2012$

\title{
Spatial and Temporal Patterns in the Distribution, Behavior, and Activity of Fishes in Canals of the Everglades
}

Ann C. Hijuelos

Florida International University, ann.hijuelos@gmail.com

DOI: $10.25148 /$ etd.FI12120504

Follow this and additional works at: https://digitalcommons.fiu.edu/etd

\section{Recommended Citation}

Hijuelos, Ann C., "Spatial and Temporal Patterns in the Distribution, Behavior, and Activity of Fishes in Canals of the Everglades" (2012). FIU Electronic Theses and Dissertations. 778.

https://digitalcommons.fiu.edu/etd/778 


\title{
FLORIDA INTERNATIONAL UNIVERSITY
}

Miami, Florida

SPATIAL AND TEMPORAL PATTERNS IN THE DISTRIBUTION, BEHAVIOR, AND ACTIVITY OF FISHES IN CANALS OF THE EVERGLADES

\author{
A thesis submitted in partial fulfillment of the \\ requirements for the degree of \\ MASTER OF SCIENCE \\ in \\ BIOLOGY \\ by
}

Ann Commagere Hijuelos 
To: Dean Kenneth G. Furton

College of Arts and Sciences

This thesis, written by Ann Commagere Hijuelos, and entitled Spatial and Temporal Patterns in the Distribution, Behavior, and Activity of Fishes in Canals of the Everglades, having been approved in respect to style and intellectual content, is referred to you for judgment.

We have read this thesis and recommend that it be approved.

$\begin{array}{r}\hline \text { Kevin Boswell } \\ \hline \text { Mike Heithaus }\end{array}$

Mike Heithaus

Joel C. Trexler, Major Professor

Date of Defense: November 2, 2012

The thesis of Ann Commagere Hijuelos is approved.

\begin{tabular}{r} 
Dean Kenneth G. Furton \\
College of Arts and Sciences \\
\hline Dean Lakshmi N. Reddi \\
University Graduate School
\end{tabular}

Florida International University, 2012 


\section{DEDICATION}

I dedicate this thesis to my loving husband, Jason Hijuelos. His support and encouragement kept me afloat and I am forever grateful he accompanied me on this journey. Thank you for your patience, understanding, sense of humor, and most importantly, sandwiches. 


\section{ACKNOWLEDGMENTS}

I wish to thank my committee members, Drs. Joel Trexler, Mike Heithaus and Kevin Boswell, for their guidance throughout this process and encouragement when things seemed bleak. I would especially like to thank my advisor, Dr. Trexler, for his unwavering trust in me and his overall positive outlook on this project. I am grateful for all the weekends he sacrificed to come out in the field and the hours he spent helping me develop and implement this study. Thank you for finding my detail-oriented (read: obsessive compulsive) nature worthy enough for working with the DIDSON. I certainly would not have survived this project without the acoustic expertise of Dr. Boswell. He graciously offered his own lab and computer space for data processing and provided valuable insight throughout the course of this project. I am truly appreciative of the feedback I received from Dr. Heithaus and his knowledge of behavioral ecology certainly enhanced the content of this thesis. My journey here would not have begun if it weren't for the guidance I received from Dr. Bill Kelso as an undergraduate at Louisiana State University. His Renewable Natural Resources course was influential in my decision to pursue this career and I am most thankful for him giving me (an unemployed, inexperienced undergraduate) a job in his lab. Thank you for semester barbeques and Hawaiian-shirt Fridays.

I owe a world of thanks to all those in the Trexler Lab who helped me in the field: Mike Bush, Jim Easton, Eric Fortman, Adriana Weill, Maya Jaffe, Harrison Duffel, and David Rosengarten. They suffered through long days and nights in the canals and patiently sat still during video recordings. An extra thanks to Eric for all his work processing DIDSON videos. Thanks to Allison Shideler, a.k.a. Big Al, for maintaining 
sanity in the lab area, and for juggling ever-changing field schedules, SAS codes, and paperwork. Her pep talks and high-fives were truly inspirational. I would like to particularly acknowledge Aaron Parker for his patience in dealing with Home Depot and all the other messes I made. A big thanks to Drs. Joe Parkos and J. Matt Hoch for being amazing sources of knowledge on all things ecology, statistics, breakfast diners, and movie quotes. Thank you for putting up with my unwillingness to drive to south Miami for lab meetings.

I would not have survived commutes to south campus without the accompaniments of Mike Bush and Nate Lemoine. Their constant distractions in the workplace may have prolonged the life of this thesis but without them, the journey wouldn't have been nearly as fun. I am forever grateful to my husband, Jason, for putting aside his Saints' tickets, parades, and his love of NOLA to accompany me on this journey. I could not have endured the Everglades, FIU, or Miami without him. Last but certainly not least, a loving thank you to my parents, Ann and Jim Commagere, and the whole Commagere-Rowley-Hijuelos crew. The phone calls, emails, care packages, and visits meant more to me than they'll ever realize.

Funding for this work was provided by award number G10AC00409 from the US Geological Survey and contract number H5000060104, task R5298110022 from Everglades National Park. 


\section{ABSTRACT OF THE THESIS \\ SPATIAL AND TEMPORAL PATTERNS IN THE DISTRIBUTION, BEHAVIOR, AND ACTIVITY OF FISHES IN CANALS OF THE EVERGLADES}

by

Ann Commagere Hijuelos

Florida International University, 2012

Miami, Florida

Professor Joel C. Trexler, Major Professor

Landscape characteristics, disturbances, and temporal variability influence predator-prey relationships, but are often overlooked in experimental studies. In the Everglades, seasonal disturbances force the spatial overlap of predators and prey, potentially increasing predation risk for prey. This study examined seasonal and diel patterns of fish use of canals and assessed predation risk for small fishes using an encounter rate model. I deployed an imaging sonar in Everglades canals to quantify density and swimming speeds of fishes, and detect anti-predator behaviors by small fishes. Generally, seasonal declines of marsh water-levels increased the density of large fishes in canals. Densities of small and large fishes were positively correlated and, as small-fish density increased, schooling frequency also increased. At night, schools disbanded and small fishes were observed congregating along the canal edge. The encounter rate model predicted highest predator-prey encounters during the day, but access to cover may reduce predation risk for small fishes. 


\section{TABLE OF CONTENTS}

CHAPTER $\quad$ PAGE

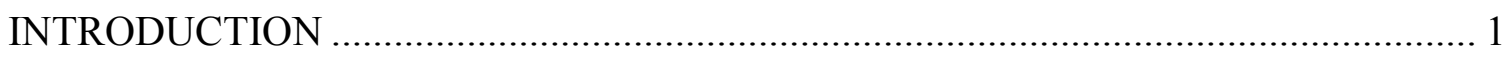

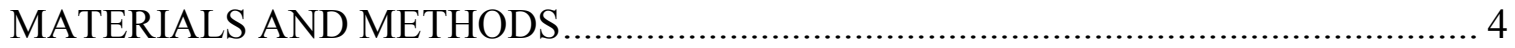

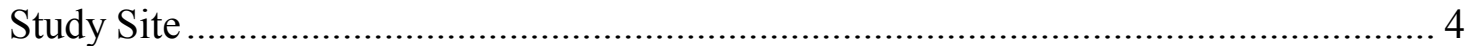

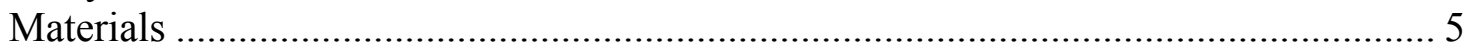

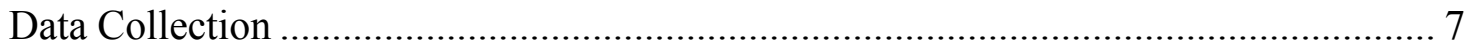

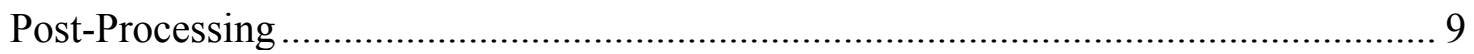

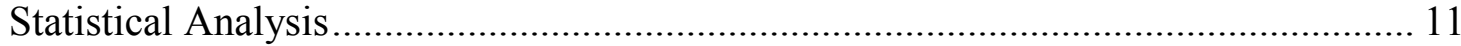

Seasonal Patterns in Fish Density and Behavior........................................................ 11

Diel Patterns in Fish Density and Activity ........................................................... 13

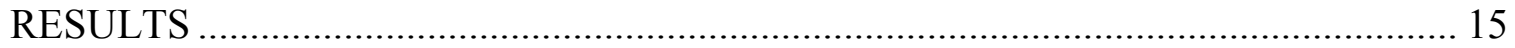

Seasonal Patterns in Fish Density and Behavior.................................................... 15

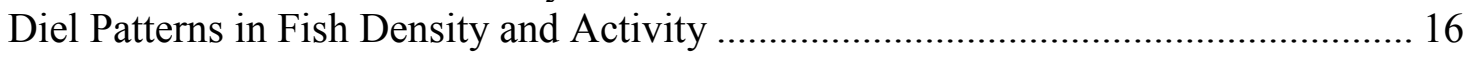

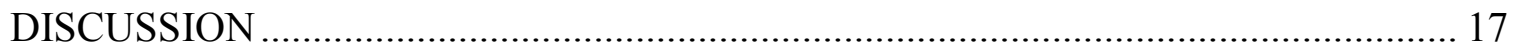

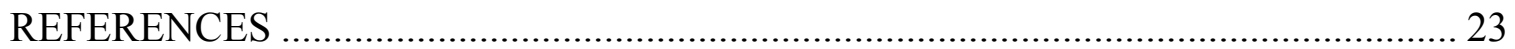




\section{LIST OF TABLES}

TABLE

PAGE

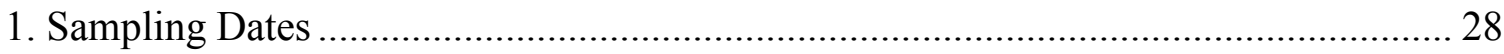

2. Results from ANCOVA for Small- and Large-Fish Densities .................................. 29

3. Model Statistics for Predicting Probability of Detecting a School ............................. 30

4. Model Fit Statistics for Predicting Nearest-Neighbor Distance and Distance-to-

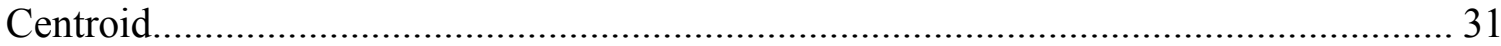

5. Results from ANOVA for Small- and Large-Fish Densities ..................................... 32 


\section{LIST OF FIGURES}

FIGURE

PAGE

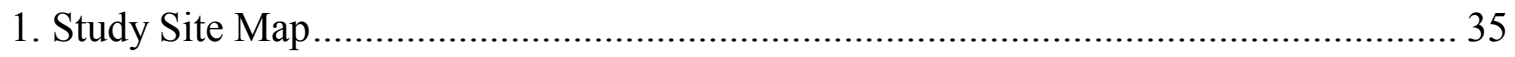

2. Mean Marsh Water-Depth Adjacent to the L67C and L31W Canals .......................... 36

3. Predicted Large-Fish Density in the L67C and L31W Canals Regressed against Marsh

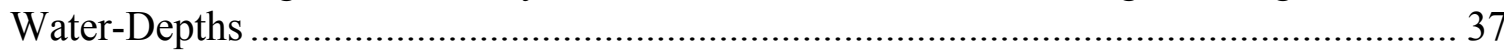

4. Partial Regression Plots of Small-Fish Density and Large-Fish Density in the L67C

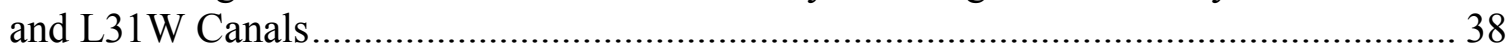

5. Probability of Detecting a School as a Function of Small-Fish Density ...................... 39

6. Partial Regression Plots of Nearest-Neighbor Distance and Small-Fish Density and Large-Fish Density in the L67C and L31W Canals................................................. 40

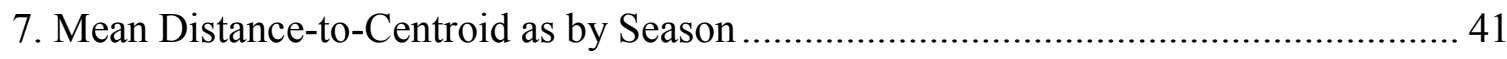

8. Mean Marsh Water-Depth Adjacent to the C111, L67C, and L31W Canals .............. 42

9. Mean Small-Fish Density by Month, Canal, and Time of Day ................................ 43

10. Mean Large-Fish Density by Month, Canal, and Time of Day .............................. 44

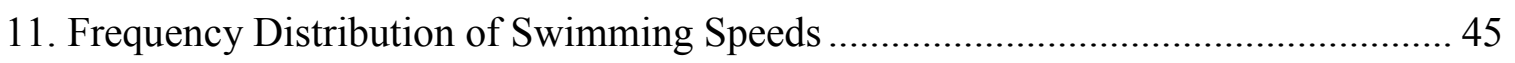

12. Mean Small- and Large-Fish Swimming Speeds by Canal and Time of Day........... 46

13. Total Encounter Rate for Schooling and Non-Schooling Prey by Time of Day and Month in the C111, L31 W, and L67C Canals .............................................................. 47 


\section{INTRODUCTION}

The configuration of the landscape is a determinant in large-scale distributions of predators and prey, and affects ecological processes that operate on local scales (Poff 1997, Turner 1989). Landscape features such as structural complexity, patchiness, and connectivity influence the movement or dispersal of individuals (Taylor et al. 1993), while localized factors (e.g., colonization rates, predation risk, and food availability) drive patch selectivity of predators and prey (Menge and Olson 1990, Verdolin 2006, Welborn et al. 1996). For instance, browsing herbivores in the African savannah make habitat-use decisions based on both proximity to waterholes and predator movements across the landscape (Valeix et al. 2009). Environmental variability and disturbances (e.g. fire, drought) also act on the landscape to influence community dynamics (Schowalter 2012, Sousa 1984, Trexler et al. 2005). Hydraulic disturbances in streams, for example, has shown to increase the impact of predatory benthic invertebrates on their prey (Lancaster 1996). Considering the interplay of landscape processes and disturbance regimes across relevant temporal scales can aid in the understanding of habitat-use decisions of predators and prey. The decision-making process of animals determines the frequency and duration of spatial overlap, and ultimately shapes predator-prey interactions.

Understanding and examining the behavioral responses of predators and prey to joint space-use is fundamental in examining predator-prey community dynamics (Lima 2002, Sih 2005). Predators may respond to the presence (or absence) of prey by aggregating in patches when prey availability is highest (Anderson 2001, Hassell and May 1974), adjusting activities or foraging modes (Gendron and Staddon 1983, 
Newlands et al. 2004), or making diel shifts in activities and habitat use (Clark et al. 2003, Løkkeborg and Fernö 1999). The inherent variability in these responses causes predation risk to fluctuate on diurnal and seasonal scales. Mobile prey may counteract predation risk with anti-predator defenses, habitat shifts, or by altering activity, foraging rates, or morphology (Creel and Christianson 2008, Lima and Dill 1990, Preisser et al. 2005, Schlosser 1987, Werner et al. 1983). The ability of prey to respond to the presence of predators is facilitated by access to cover, refuge, or other landscape features, and this may ultimately influence the decision-making process of prey (Heithaus et al. 2009).

Traditional foraging models developed to understand and predict patch-use decisions (e.g., optimal patch use, ideal free distribution [Fretwell and Lucas 1969, Pyke et al. 1977]) have expanded to incorporate freely interacting predators and prey (e.g., game theory [Brown et al. 1999, Hugie and Dill 1994, Lima 2002, Sih et al. 1998]). These advancements improve our predictive ability of community dynamics, but considering the behavioral responses of predator and prey in the context of heterogeneous landscapes and temporal environmental variability would provide additional insight into the decision-making process of animals.

Canals of the Florida Everglades provide an ideal setting for exploring predator and prey distributions and subsequent behavioral responses. Although rarely studied, canals harbor large-bodied piscivores and serve as aquatic refuges for small and large fishes during periods of low marsh water-levels (Loftus and Kushlan 1987, Rehage and Trexler 2006). Seasonal and regional fluctuation in water levels limits connectivity between the canal and adjacent wetlands and may ultimately control the spatial overlap of small and large fishes in canals. Limited access to the adjacent vegetated marsh during 
the dry season may impede prey's ability to avoid predators, and impose a predation risk for prey. Gut contents of several species of large fishes found in canals (e.g., Florida gar, largemouth bass, bullhead catfish, and sunfishes) have shown small fishes to be a dominant food source (Loftus 2000), indicating the risk of predation in canals is potentially high for small fishes. It has been suggested that the relationship of piscivorous fishes and small prey fishes is mainly influenced by wetland hydroperiod and access to canals (Chick et al. 2004, Trexler et al. 2005), but it is unknown how predators and prey respond behaviorally to joint space-use of canals across diel and seasonal scales and in the context of connectivity to the adjacent wetland.

The objective of this study was to examine diel and seasonal patterns of canal habitat use by small and large fishes, and use an encounter-rate model to assess the level of risk associated with these canals for small fishes. I deployed a high-resolution imaging sonar (DIDSON, Dual-frequency Identification Sonar) to quantify the density of large and small fishes, detect anti-predator behaviors by small fishes, and document activity among canals. I predicted small- and large-fish densities would exhibit seasonal increases in canal habitat-use in response to decreasing water levels in adjacent marshes. Regional changes in the timing and delivery of water would cause this response to vary among canals. I predicted schooling frequency of small fishes would increase as the density of large fishes increased and as a response to increased threat of predation. I also expected these schools would become more compact in shape, typical of anti-predator behavior in fishes. I predicted small- and large-fish densities and swimming speeds would decrease at night because of decreased foraging opportunities from reduced visual cues. 


\section{MATERIALS AND METHODS}

\section{$\underline{\text { Study Site }}$}

I studied the temporal distribution of fishes in three canals that varied in their connectivity to adjacent marsh habitats. The potential for fishes to swim between the canals and surrounding wetlands is highly variable in the Everglades because of seasonal changes in local and regional rainfall and water management. The L67C canal $\left(25.767865^{\circ} \mathrm{N},-80.673309^{\circ} \mathrm{W}\right)$ separates Water Conservation Area (WCA) 3B from the Gap region and is bordered by a levee on its eastern edge and long-hydroperiod wetlands (flooded $>300$ days per year) on its western edge (Figure 1). The canal is approximately $10 \mathrm{~m}$ wide and $3.5 \mathrm{~m}$ deep with a large littoral zone connecting the canal to the surrounding wetlands. Dense patches of periphyton intermixed with submerged aquatic vegetation line the canal-marsh edge. The L31W canal $\left(25.398489^{\circ} \mathrm{N},-80.572974^{\circ} \mathrm{W}\right)$ is bordered by short-hydroperiod wetlands (flooded $<300$ days per year) of Everglades National Park (ENP) on its western edge and a levee on its eastern edge. The canal morphology is similar to the L67C, but fish access to the marsh edge is limited during periods of low water. The $\mathrm{C} 111$ canal $\left(25.289333^{\circ} \mathrm{N},-80.445068^{\circ} \mathrm{W}\right)$ is also bordered by short-hydroperiod wetlands (flooded $<300$ days per year) of ENP on its western edge and fishes have limited access to the marsh edge when water levels recede. It is also considerably larger than the other two canals, $35 \mathrm{~m}$ wide and $5 \mathrm{~m}$ deep.

Three sites were established in both the L67C and L31W canals for addressing the seasonal component of the study. The site locations were selected to be adjacent to areas with ongoing studies of fish ecology in the adjacent marshes and three subsamples were collected at each site. To assess diel variation in fish behavior and activity, six additional 
sites within the L67C, $\mathrm{L} 31 \mathrm{~W}$ and $\mathrm{C} 111$ canals were selected using the Create Random Points tool in ArcGIS 10 (ESRI). Sites were constrained to be at least 200 meters apart and accessible from a boat launch. Three sets of six points were created and upon field inspection, an individual site was selected out of the three possible locations. Sites were selected such that among sites, cover and submerged aquatic vegetation density was similar and no physical structures prevented data collection.

\section{$\underline{\text { Materials }}$}

A Dual-frequency Identification Sonar (DIDSON) was deployed to quantify density, length, swimming speeds, and behavior of fishes. The DIDSON is a multi-beam, imaging sonar that records high-resolution, acoustic data at short ranges $(<30 \mathrm{~m})$. Originally developed by the University of Washington's Applied Physics Laboratory for military applications, it has been adapted by fisheries biologists to observe fish behavior (Moursund et al. 2003, Tiffan et al. 2010) and estimate fish abundance and size (Boswell et al. 2008, Burwen et al. 2010, Han et al. 2009, Holmes et al. 2006, Tiffan et al. 2004). The sonar is advantageous over underwater video cameras in its ability to record at night and in turbid conditions without any modifications or artificial lighting (Maxwell and Gove 2007, Moursund et al. 2003). The sonar is also capable of ensonifying individual fish located directly behind other individuals, which may have otherwise gone undetected using optical methods.

The DIDSON is capable of recording images at distances of $60 \mathrm{~m}$ from the unit when operating at low frequency $(1.1 \mathrm{MHz})$ or to $15 \mathrm{~m}$ at high frequency $(1.8 \mathrm{MHz})$. The DIDSON transmits 48 beams (1.1 MHz) or 96 beams ( $1.8 \mathrm{MHz})$ with 512 samples per beam, ensonifying an area $29^{\circ}$ in the horizontal axis and $14^{\circ}$ in the vertical axis. The 
acoustic data are represented as two dimensional images, displaying the horizontal dimensions while suppressing the vertical, when deployed horizontally. The resolution of the image is a function of the window length (i.e., the specified length of the area sampled) and varies depending on the range of interest, such that objects further away are viewed at a lower resolution than those closer. For this study, the DIDSON was deployed in high-frequency mode to maximize resolution. Window length during the seasonal study was originally set at $10 \mathrm{~m}$, but reduced to $5 \mathrm{~m}$ to improve imaging of small fishes. For the diel component of the study that focused on schooling prey and predator behavior, the window was set to $10 \mathrm{~m}$ (Table 1). For all window lengths, the starting distance was $1.67 \mathrm{~m}$ from the sonar and extended outwards toward the canal-marsh edge either 5 or $10 \mathrm{~m}$.

Although acoustic sampling generally alleviates problems associated with direct capture techniques (see Lucas and Baras 2000 and references therein), sonar images do not contain enough detail to distinguish among species, particularly for small fishes. As a result, fish were categorized as small $(<12 \mathrm{~cm})$ or large $(>20 \mathrm{~cm})$ based on their total length. Fish in the medium size category $(12-20 \mathrm{~cm})$ were excluded from my analysis. The classification scheme represents an assemblage of prey and piscivores, respectively. Small fish in the Everglades are typically defined as fish $<8 \mathrm{~cm}$ (Trexler et al. 2001) and in the canals are dominated by cyprinodontids, poecilids, and juvenile centrarchids (Loftus and Kushlan 1987). Juvenile centrarchids (Lepomis spp., especially $L$. punctatus), eastern mosquitofish (Gambusia holbrooki), and brook silverside (Labidesthes sicculus) have been observed schooling in the canals (Loftus and Kushlan 1987, J. Trexler pers. comm.). The small-fish category was increased to include fish up 
to $12 \mathrm{~cm}$ to account for overestimation of lengths (Burwen et al. 2010). Large piscivores include largemouth bass (Micropterus salmoides), Florida gar (Lepisosteus platyrhincus), bowfin (Amia calva), and adult centrarchids (Lepomis spp.) (Chick et al. 2004).

\section{$\underline{\text { Data Collection }}$}

Seasonal acoustic data were collected monthly during daylight hours in the L67C and L31W canals in the early-dry season (December 2010 - March 2011), dry season (April - June 2011, and wet season (July - October 2011) to capture seasonal fluctuation in marsh water-levels. Equipment malfunction prevented a July 2011 sample. To maintain a balanced sampling design across seasons, the December 2010 data were excluded from analysis. The DIDSON was deployed horizontally off the side of a stationary boat, approximately $20 \mathrm{~cm}$ below the surface and directed perpendicular to the

canal-marsh edge. Additional videos were collected towards the center, deeper portion of the canal and preliminary analyses suggested fish, particularly smaller prey, were not uniformly distributed. As a result, the present study focused on the canal-marsh interface, where fish densities would be highest. The unit was angled $4-7^{\circ}$ downward to maximize video quality and target detection. A laptop computer on the boat provided live-viewing of the DIDSON image and enabled adjustments to the sonar if necessary. Acoustic data were collected at 5 to 7 frames $\mathrm{s}^{-1}$ for five minutes with a set window length of 5 or $10 \mathrm{~m}$ (Table 1$)$.

Diel acoustic data of fish activity and behavior were collected during the dry season in the L67C, L31W, and C111 canals from February 2012 through May 2012. Day-time collection began at least one hour after sunrise and concluded mid-afternoon. The subsequent night sample was collected within three nights of the day sample, 
beginning at least one hour after sunset. Inclement weather prevented data collection during some sampling periods and locations (Table 1). A floating mount was used to suspend the DIDSON in the upper portion of the water column (approximately $20 \mathrm{~cm}$ below surface) and a four-point anchor system was used to secure the float to the bottom of the canal. Use of this platform reduced movement in the DIDSON, resulting in stable background data that improved subsequent analysis. Acoustic data were collected at each site at 5-7 frames $\mathrm{s}^{-1}$ for 15 minutes with a window length of $10 \mathrm{~m}$. Each site was visited once per sampling event.

Water levels in the adjacent wetlands were obtained from the Everglades Depth Estimation Network (EDEN, http://sofia.usgs.gov/eden/) and were used as a proxy for landscape connectivity. Water depth information was provided on $400 \mathrm{~m}^{2}$ grids. Grids adjacent to each site were selected and water depth was estimated for use in calculating marsh water-depth and days of connectivity between the canal and marsh surface. Connectivity was defined for small fishes as marsh water-depth $>5 \mathrm{~cm}$ (Trexler and Goss 2009), while for large fishes marsh water-depths $>15 \mathrm{~cm}$. Chick et al. (2004) defined connectivity for large (> 8cm TL) fishes as marsh water-depths $>10 \mathrm{~cm}$, but since the large-fish category in this study was fish $>20 \mathrm{~cm}$, I increased the marsh water-depth threshold to account for larger body sizes. At these depths, fishes are assumed to move freely between the marsh and canal habitats. Days of connectivity ranged from negative (number of days without connectivity) to positive (number of days with connectivity). The negative value indicates the number of days since the marsh was last connected to the canal, and the positive value represents the number of days since the canal reconnected to the adjacent marsh. 


\section{Post-Processing}

Seasonal acoustic data collected from January 2010 to October 2011 were processed using DIDSON topside software (SoundMetrics Corp., V5.25.28) and ImageJ (V1.47a, http://rsb.info.nih.gov/ij/). Acoustic scattering intensity values (dB) of the 96 beams within each frame were analyzed to display the maximum per-sample value across all beams within each frame, yielding an echogram with window range on the $\mathrm{Y}$ axis and time on the $\mathrm{X}$ axis. The echogram was displayed in unison with the raw DIDSON footage to assist in fish detection. Actively swimming fish were manually marked on the echogram using the DIDSON software and lengths derived from manual measurements using the "measure tool" in the DIDSON software. The threshold slider was adjusted when necessary to reduce background noise and improve target detection. Vegetation within the video may have decreased the probability of detecting fish and biased density estimates downward. It was assumed any diminution in detectability is randomized across space and time. When a large school of fish $(>10)$ was present, the lengths of at least three fish were measured and the average of those measurements was applied to all

fish in the school. A school was defined in the present study as a social assembly of fish that exhibited unified changes in direction or speed or were clustered in distinct groups (e.g., bait balls) (Pitcher and Parrish 1992).

I used the ImageJ software (V1.47a) to characterize schools of fish, including estimating the number fish in the school, nearest-neighbor distance, and mean distance to school center. To process schools in ImageJ, a single frame (snapshot) of the school was exported as a jpeg-formatted file and imported into ImageJ. An outline was created around the school and the area outside the outline was deleted. This school image was 
converted to grayscale and contrast thresholds were applied to distinguish schooling individuals from the background. The school was then converted to a binary image, with schools pixilated white and background pixilated black. The conversion of the original image to binary resulted at times in multiple fish being clumped together as one. Subtracting the static background prior to exporting the image from the DIDSON software and adjusting the contrast thresholds in ImageJ improved target definition and reduced this clumping effect.

The Analyze Particles tool in ImageJ was used to export the total number of fish in a school and the center coordinates of each fish. The school's centroid was calculated as the average of the fish coordinates. Mean distance-to-centroid was the straight-line distance of each fish to the centroid, averaged across fish. Mean nearest-neighbor distance (NND) was calculated as the straight line distance between an individual fish and the nearest fish (NND macro from Yuxiong Mao, https://icme.hpc.msstate.edu/). Current technology limited the representation of three-dimensional schools to twodimensions resulting in imperfect calculations of these metrics. Nonetheless, this analysis is appropriate for looking at relative differences among schools. Individual fish counts, lengths, and schooling metrics were exported from the DIDSON software and ImageJ as text files for data analysis. Fish abundance was standardized as density per 5 minutes (length of video) by dividing the counts in a single video by the area of the video image. Standardizing density allowed for comparison of data collected at the $5 \mathrm{~m}$ and 10 m window lengths.

Diel acoustic data collected between February and May 2012 were processed in Echoview (version 5.2.59) using a semi-automated analysis pathway (Boswell et al. 
2008). The 15-minute data files were stratified into 30 -second sub-samples and ten were randomly selected for analysis. Sub-sampling reduced the probability of counting the same fish twice within an interval, while still providing a sufficiently long window to track fish and calculate their speed. The image enhancement and multibeam single-target detection methods described as "Process 3" by Boswell et al. (2008) enabled the calculation of fish abundance, length, and speed. At times, manual counting and length measurements were required when fish were undetected by the semi-automated process or when fish were closely spaced. As a result, speed was not calculated for those individuals. Fish were then categorized as small fish $(<12 \mathrm{~cm})$ or large fish $(>20 \mathrm{~cm})$ as previously described. Schools were processed in ImageJ to calculate number of individuals, mean nearest-neighbor, and mean distance-to-centroid. The number of individuals in each school was then added to the "small fish" category and all metrics were averaged across the 10 intervals to produce small-fish density, large-fish density, mean nearest-neighbor and mean distance-to-centroid for each DIDSON video.

\section{$\underline{\text { Statistical Analysis }}$}

\section{Seasonal Patterns in Fish Density and Behavior}

Small- and large-fish densities were analyzed separately with analysis of covariance (ANCOVA) using restricted maximum likelihood estimation (Proc MIXED; SAS V9.2). The Durbin-Watson statistic was used to test for autocorrelation in the residuals and significance tests indicated first-order autocorrelation was present $(\mathrm{p}<0.05)$. A first-order autoregressive covariance structure was applied to account for correlation in fish densities between sampling events (Proc MIXED; SAS V9.2). Season and canal were treated as fixed effects and marsh water-depth was a covariate. In the 
small-fish model, large-fish density was also used as covariate. Covariates were nested within canal to account for spatial variability among canals. Large-fish density was square-root transformed and small-fish density was natural-log transformed to meet the assumption of normality. The smallest non-zero observed value was added as a constant prior to all natural-log transformations described in this study. Shapiro-Wilk tests on models residuals confirmed that these transformations satisfied the assumption of normality. Plots of residuals versus predicted values and QQ plots of residuals were also inspected to assess homogeneity of variance and linearity of model.

Nearest-neighbor distance and distance to school's centroid were analyzed with ANCOVA models using maximum likelihood techniques. Canal and season were treated as fixed effects while marsh water-depth, large-fish density, and small-fish density were covariates. Schooling metrics and marsh water-depth were natural-log transformed. Covariance structure, fish-density transformations, and tests of model assumptions were conducted as described for the seasonal fish-density analysis. I used Akaike's information criterion with the small sample size adjustment (AICc) to compare various nested and unnested models and to objectively determine the most appropriate model to describe the data (Anderson 2008). The AICc scores for the models were standardized by subtracting the minimum AICc from each AICc score and then ranked based on $\triangle \mathrm{AICc}$ (smaller is better). All plausible models were assessed by generating Akaike weights as the probability that a given model is the best among all candidate models. The ratio of Akaike weights for any two models computes an evidence ratio, and can be used to provide support for one model over another. I calculated evidence ratios for the best model $(\triangle \mathrm{AICc}=0)$ versus all other models such that the larger the evidence ratio, the 
stronger the empirical support for the best model. Goodness of fit was also calculated using pseudo- $\mathrm{R}^{2}$ :

$$
R^{2}=1-\exp \frac{-\{-2[\log L(0)-\log L(p)]\}}{n}
$$

where $\log \mathrm{L}(0)$ is the $\log$-likelihood of the model containing only an intercept term, $\operatorname{logL}(\mathrm{p})$ is the $\log$-likelihood for the fitted model with $p$ covariates, and $n$ is sample size.

Schooling events were modeled as a binary response (school present versus school not present) using logistic regression fit by maximum likelihood estimation. Individual samples within a site were treated independently in this analysis. I tested for the effect of canal, days of connectivity, small-fish density and large-fish density on the probability of detecting a school. I tested various nested and unnested models and compared $\triangle \mathrm{AICc}$ scores to select the best model, as described above.

\section{Diel Patterns in Fish Density and Activity}

Diel patterns in fish density and activity were examined during the dry season when limited access was available to the adjacent marsh. Small- and large-fish densities were analyzed with ANOVA to test for effects of time of day (day and night), canal (L67C, L31W, and C111) and month (February, April, and May). Covariance structure was applied to the small-fish model only, as described for previous analyses. The density of large fish was initially used as a covariate in the small-fish model, but no significant differences were detected at $\alpha=0.05$, thus the covariate was removed from the model. Densities were natural-log transformed to meet model assumptions as previously described. Small- and large-fish swimming speeds were analyzed with ANOVA to test for effect of time of day, canal, and month. Speeds were natural-log transformed. 
Frequencies of schooling events in the $\mathrm{L} 67 \mathrm{C}, \mathrm{L} 31 \mathrm{~W}$, and $\mathrm{C} 111$ were compared among months and canals using logistic regression. Time of day was excluded from the analysis because schools were observed exclusively during the day.

I calculated encounter rate of small and large fishes using Gerritsen and Strickler's (1977) model as:

$$
z_{p}=\pi R^{2} N_{u} \frac{\left(u^{2}+3 s^{2}\right)}{3 s}
$$

where $Z_{p}$ is the encounter rate of an individual predator with its prey population (no. prey $\left.\mathrm{s}^{-1}\right) ; R$ is the detection distance; $N_{u}$ is prey density; $u$ is prey swimming speed; and $s$ is predator swimming speed. I used two different calculations of prey density to assess the role of schooling on encounter rates. First, I calculated prey density as the sum of all prey in a given time interval, divided by the volume of the DIDSON video which was treated as a rectangular prism. I then assumed a predator would only be able to capture one prey from a school, regardless of school size, so prey density was revised by treating each school as one fish (Turesson and Brönmark 2007). Prey density was then defined as the mean number of fish (no. $\mathrm{m}^{-3}$ ) by canal, time of day, and month. The reaction distance variable is a squared term and consequently, is the most sensitive variable in the model (Muirhead and Sprules 2003). I used published values of largemouth bass (Micropterus salmoides) detection distances of prey at different light levels (McMahon and Holanov 1995): $0.5 \mathrm{~m}$ at night and $2 \mathrm{~m}$ during the day. I then calculated total encounter rate of all predators with their prey population in an hour time frame as:

$$
Q=Z_{p} \cdot N_{p}
$$

where $Z_{p}$ is predator encounter rate and $N_{p}$ is predator density (no. $\mathrm{m}^{-3}$ ). 


\section{RESULTS}

\section{$\underline{\text { Seasonal Patterns in Fish Density and Behavior }}$}

Water levels dropped considerably during the study, reducing connectivity between the canals and surrounding wetlands (Figure 2). The seasonal decrease in marsh water-levels occurred in November 2010 in the L31W, but not until February 2011 in the L67C. The onset of wet-season conditions occurred earlier in the L31W as well, whereby marsh-water levels increased above $5 \mathrm{~cm}$ in August 2011, but not until October 2011 in the L67C. The effect of marsh water-levels on fish density was different between the L31W and L67C canals. In the L67C, large-fish density was negatively correlated with marsh water-levels $(\mathrm{p}<0.05)$ and as a result, was lowest during the wet season $(0.20$ fish $\mathrm{m}^{-2}$; Figure 3). Conversely, large-fish density in the L31W was lowest during the early dry season (0.20 fish $\mathrm{m}^{-2}$ versus 1.37 fish $\mathrm{m}^{-2}$ wet season; Figure 3$)$, but showed no significant response to marsh water-depths (Table 2).

Contrary to the large-fish, small-fish density did not vary with marsh water-depth (Table 2) and did not vary seasonally within either canal. A positive relationship was detected, however, between small and large-fish density in the L67C ( $p=0.04$; Figure 4). I did not detect a relationship between small and large fish density in the L31W, and small-fish densities were $85 \%$ lower than in the L67C.

The probability of detecting a school was best described by models that included canal and large and small-fish densities (Table 3). The top five models with the lowest $\triangle \mathrm{AICc}$ score fit the data equally well, so I selected the most parsimonious model to predict schooling frequency, which only included small-fish density. The small-fish 
density model predicted that the probability of detecting a school increased above $50 \%$ when density of small fish was great than 5 fish $\mathrm{m}^{-2}$ (Figure 5).

Predicting mean nearest-neighbor distance in schools was best supported by the model that incorporated canal, large-fish density, and small-fish density (Table 4). Nesting the covariates within canal and removing the canal main effect from the model also performed well. Preference for these two models was supported by the evidence ratio for the next best model that excluded canal altogether (evidence ratio: 6 ). The model predicted mean nearest-neighbor distance of schooling fish decreased as small-and large-fish densities increased (Figure 6). This relationship was detected in both canals but was strongest in the $\mathrm{L} 67 \mathrm{C}$.

The best performing model for predicting mean distance to school's centroid included season as a main effect. The next best model included small-fish density as a covariate and season as a main effect. Several other models had $\Delta \mathrm{AIC}<3$ and evidence ratios $<5$, but these models also yielded low $\mathrm{R}^{2}$ values (Table 4). The season-only model showed distance to centroid was smallest during the dry and wet seasons relative to the early-dry season (Figure 7).

Diel Patterns in Fish Density and Activity

Marsh water-depths were approximately $10 \mathrm{~cm}$ in the L67C and C111 and $5 \mathrm{~cm}$ in the L31W at the start of the diel study (Figure 8). All canals exhibited declines in water levels during the study, but marsh water-levels began to increase above $15 \mathrm{~cm}$ in the C111 and L31W canals by May. A significant interaction between time of day, month, and canal was detected for small- and large-fish densities (Table 5). Significant declines in small-fish density from day to night were only detected in the L67C (up to 95\% 
decrease in densities), while no differences between day and night were detected in the L31W (Figure 9). Small-fish density increased from day to night in the C111 in April (5.6\% increase). Large-fish density declined significantly only in the L31W in May (Figure 10).

Frequency distributions of swimming speeds revealed the majority of small-fish swim at speeds between $5-15 \mathrm{~cm} \mathrm{~s}^{-1}$ and large fish at $5-20 \mathrm{~cm} \mathrm{~s}^{-1}$, with occasional occurrences of faster individuals in both size classes (Figure 11). A significant decline in fish swimming speed from day to night was detected only in the C111 (Figure 12).

The encounter rate model predicted more predator-prey encounters per hour during the day than at night, with rates being near zero at night across all canals (Figure 13). Under the assumption that predators can encounter and capture only one prey in a school, daytime encounter rates dropped dramatically versus those in which all fish had equal probability of being captured. For instance, when schools were treated as one fish, encounter rates ranged from 0 to 5 fish $\mathrm{m}^{-3} \mathrm{~h}^{-1}$ in the $\mathrm{L} 31 \mathrm{~W}$ and $\mathrm{L} 67 \mathrm{C}$ canals and 0 to 1.5 fish $\mathrm{m}^{-3} \mathrm{~h}^{-1}$ in the $\mathrm{C} 111$. Conversely, assuming all individuals in a school can be

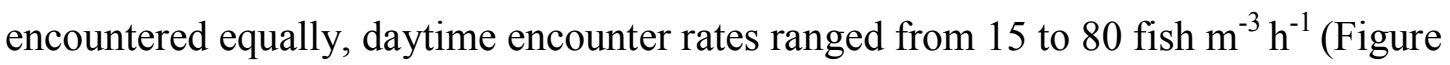
13C).

\section{DISCUSSION}

Landscape characteristics, environmental disturbances, and temporal variability influence predator-prey relationships, but are often overlooked in experimental studies. My study used an observational field-based approach to examine seasonal and diel patterns in the spatial overlap of small and large fishes in deep-water refuges, and explore 
their relationship in the context of varying connectivity to the adjacent wetland. Patterns were not always uniform among canals, highlighting the importance of incorporating spatial and temporal gradients in evaluating predator-prey relationships.

As predicted, large-fish density was negatively correlated with water depth of the adjacent wetland, but only in the L67C canal. A significant decline in large-fish density was also detected with the onset of the wet season in the L67C, suggesting large fishes were dispersing out of the canal and into the adjacent marsh. In the $\mathrm{L} 31 \mathrm{~W}$, a $360 \%$ increase in large-fish density was detected from the early dry to dry season, but no change from the dry to wet season. The initial increase may reflect decreases in canal depth or water quality, reducing available habitat and causing fishes to congregate along the edge and upper portion of the water column, where acoustic data were recorded. Despite increasing water levels in the adjacent marsh with the onset of the wet season, large-fish density remained high in the canal (1.4 fish $\left.\mathrm{m}^{-2}\right)$, indicating fishes did not immediately disperse into the neighboring marshes. The $\mathrm{L} 31 \mathrm{~W}$ is adjacent to a shorthydroperiod wetland (flooded $<300$ days per year) and as a result, large fishes are reliant on deep-water refuges for much of the year. Choosing not to disperse in the adjacent marsh may be a learned behavior and cost-effective strategy for large fishes. Tracking data on Mayan cichlids, largemouth bass, and bowfin shows many individuals do not travel far from the canal, while others disperse several kilometers (J. Parkos, M. Bush, and J. Trexler, unpublished data). Additional research into the movement patterns of these predators aims to elucidate the underlying mechanism driving their decisions to disperse. 
No relationship was detected between marsh water-levels and small-fish density in either canals. Water levels in the marshes adjacent to the $\mathrm{L} 31 \mathrm{~W}$ were well below the small-fish threshold (5 cm; Trexler and Goss 2009) during the early-dry season, so it is likely that small fishes dispersed into the canal prior to the start of this study.

Conversely, water levels in the $\mathrm{L} 67 \mathrm{C}$ dropped below the threshold from the early dry to dry season, yet no difference in small-fish density was detected across seasons. The ability to respond to decreasing water levels was noted by Rehage and Trexler (2006), who recorded a $200 \%$ increase in small-fish $(<8 \mathrm{~cm}$ TL) density in marshes adjacent to the C111 canal with the onset of the dry season. It is possible that the initial flux of small fishes into the $\mathrm{L} 67 \mathrm{C}$ canal happened prior to sampling, as was noted with the $\mathrm{L} 31 \mathrm{~W}$. Alternatively, small fishes may have had access to refuge along the very edge of the marsh and withheld moving into the L67C until the refuges were unavailable $(<5 \mathrm{~cm}$ water depth). A large increase (> 155\%) in small-fish density was observed in the L67C from May to June and again from June to August 2011, when the surrounding marshes were completely dry. This analysis sought to explore seasonal variation in fish use of canals, but canal habitat use for small fishes may happen on shorter temporal and spatial scales than large fishes. Additional sampling during periods of decreasing water levels and exploring the role of microtopography may offer resolution on the timing and duration of small fish use of canals.

The seasonal movement of fishes into the canal led to the development of daytime schools when prey density increased above 5 fish $\mathrm{m}^{-2}$ (Figure 5). The schooling response may explain the positive relationship detected between large-fish density and small-fish density. In the presence of predators, fish form schools as an anti-predator tactic to 
reduce the probability of being consumed (Parrish 1991, Pitcher and Parrish 1992). This assumes small prey recognized and responded to the threat of predation. Small fish in the Everglades have multiple generations per year and it could be argued those entering canals are naïve to large predatory fishes. Rehage et al.(2009) tested the role of naiveté for eastern mosquitofish (Gambusia holbrooki), a numerically dominant prey item in the Everglades, by exposing them to a predator they readily encounter and a novel predator infrequently encountered. Behavioral responses of prey were observed in the presence of either predator via schooling and altering microhabitat use, suggesting prey naiveté did not impede their ability to detect and recognize predators. Consequently, the increased presence of schools is likely an emergent outcome of increased threat of predation from predatory fishes in canals. This is supported by the school structure, because schools were tightly grouped as their density, along with large-fish density, increased. This relationship was strongest in the $\mathrm{L} 67 \mathrm{C}$, suggesting other factors, such as microhabitat characteristics, may be more important drivers in the distribution of small fishes in the L31W. Habitat selection within the L31W could play an important role in structuring fish communities (Magoulick and Kobza 2003), with cypress, willow, and pond apple providing cover along the edge and refuge from predators. Additional research is necessary to understand how cover and submerged aquatic vegetation influence the decision-making process of individual fish.

The diel patterns in canal habitat use were not uniform among canals. Declines in small-fish density at night only occurred in the L67C, while an increase was observed in the C111 in April. One possible explanation is that small fishes made horizontal migrations into the shallow portions of the littoral zone or adjacent marsh to forage or 
reduce risk from nocturnal piscivores. If access to the marsh was limited, as in the C111 in April, prey may have opted to congregate along the canal-marsh edge, which would explain the increase in density. Diel horizontal migrations have been observed in lakes, but in the reverse direction, from the littoral zone to the pelagic zone at night for foraging opportunities (Gaudreau and Boisclair 1998, Hall et al. 1979, Naud and Magnan 1988). In the Everglades, small fishes feed on invertebrates that live in periphyton mats and flocculent benthic detritus (Dorn et al. 2006), which are abundant along the canal-marsh edge. This may explain the reverse direction of the horizontal migration.

No diel pattern was detected in large-fish density, except for the L31W in May when a decrease in density was observed at night. Overall, large-fish densities in the diel study were relatively low, which could be an artifact of sub-sampling of data. A longer sub-sample time interval (> $30 \mathrm{sec}$.) may be more appropriate to capture the full range of large-fish densities in these canals. Alternatively, a larger window length (>10 m) may be needed to accurately census large fishes in these canals, particularly the C111, which is three times as wide as the other two canals. The low range of large-fish densities detected in the diel study may also explain the lack of a significant relationship between small and large fishes.

The encounter rate model in this study predicted highest encounters during the day versus night, and this difference was largest when individual fish in a school were included in the model. Treating schooling fish as one individual, under the assumption that predators can only capture one prey out of the school, resulted in lower encounter rates during the day. Encounter rates can be used a proxy for predation risk and the results of this model suggest risk is lowest for all individuals when schools are present. It 
is unclear how the presence of schooling fish affects the predation risk for individuals not schooling. Further, prey's proximity to the littoral zone and vegetation structure (i.e., predation refuge) can lower the capture efficiency of predators, so incorporating likelihood-of-capture or access-to-refuge may improve model predictions. Additional diel sampling along a marsh water-depth gradient would also provide insights into how predator-prey encounters in the canal are mediated by access to prey refuge via the littoral zone or marsh surface. In addition to piscivorous fish, small fish are also at risk of predation from wading birds. Vulnerability to capture is greatest at water depths $<19$ cm (Gawlik 2002), and as a result, this predation risk is likely highest in the marshes adjacent to the canal, and not in the canal itself.

The results from both the seasonal and diel studies highlight the importance of assessing predator-prey relationships across environmental gradients (e.g., water depth, landscape connectivity) to accurately predict the responses of prey to predator abundance. In this study, seasonal reductions in marsh water-levels caused predators to move into the canals, increasing predation risk, resulting in anti-predator behavior by prey in the form of schooling. At night, schools disbanded and individual prey congregated along the edge or possibly made horizontal movements into the adjacent marsh. The diel patterns in prey space use suggest prey may increase foraging effort at night when the threat of predation is reduced. This research provides new insight into the behavioral responses of mobile predators and prey in the Everglades and facilitates our understanding of the role of environmental gradients in shaping these interactions. 


\section{REFERENCES}

Anderson DR. 2008. Model Based Inference in the Life Sciences: A Primer on Evidence. New York, NY: Springer Science Business Media, LLC.

Anderson T. 2001. Predator Responses, Prey Refuges, and Density-Dependent Mortality of a Marine Fish. Ecology 82: 245-257.

Boswell KM, Wilson MP, Cowan JH. 2008. A Semiautomated Approach to Estimating Fish Size, Abundance, and Behavior from Dual-Frequency Identification Sonar (DIDSON) Data. North American Journal of Fisheries Management 28: 799-807.

Brown JS, Laundre JW, Gurung M. 1999. The Ecology of Fear: Optimal Foraging, Game Theory, and Trophic Interactions. Journal of Mammalogy 80: 385-399.

Burwen D, Fleischman S, Miller J. 2010. Accuracy and Precision of Salmon Length Estimates Taken from DIDSON Sonar Images. Transactions of the American Fisheries Society 139: 1306-1314.

Chick JH, Ruetz CR, Trexler JC. 2004. Spatial Scale and Abundance Patterns of Large Fish Communities in Freshwater Marshes of the Florida Everglades. Wetlands 24: 652-664.

Clark KL, Ruiz GM, Hines AH. 2003. Diel Variation in Predator Abundance, Predation Risk and Prey Distribution in Shallow-Water Estuarine Habitats. Journal of Experimental Marine Biology and Ecology 287: 37-55.

Creel S, Christianson D. 2008. Relationships between Direct Predation and Risk Effects. Trends in Ecology \& Evolution 23: 194-201.

Dorn N, Trexler J, Gaiser E. 2006. Exploring the Role of Large Predators in Marsh Food Webs: Evidence for a Behaviorally-Mediated Trophic Cascade. Hydrobiologia 569: 375-386.

Fretwell SD, Lucas HL. 1969. On Territorial Behavior and Other Factors Influencing Habitat Distribution in Birds. Acta Biotheoretica 19: 16-36.

Gaudreau N, Boisclair D. 1998. The Influence of Spatial Heterogeneity on the Study of Fish Horizontal Daily Migration. Fisheries Research 35: 65-73.

Gawlik DE. 2002. The Effects of Prey Availability on the Numerical Response of Wading Birds. Ecological Monographs 72: 329-346.

Gendron RP, Staddon JER. 1983. Searching for Cryptic Prey: The Effect of Search Rate. The American Naturalist 121: 172-186. 
Gerritsen J, Strickler JR. 1977. Encounter Probabilities and Community Structure in Zooplankton: A Mathematical Model. Journal of the Fisheries Research Board of Canada 34: 73-82.

Hall DJ, Werner EE, Gilliam JF, Mittelbach GG, Howard D, Doner CG, Dickerman JA, Stewart AJ. 1979. Diel Foraging Behavior and Prey Selection in the Golden Shiner (Notemigonus crysoleucas). Journal of the Fisheries Research Board of Canada 36: 1029-1039.

Han J, Honda N, Asada A, Shibata K. 2009. Automated Acoustic Method for Counting and Sizing Farmed Fish During Transfer Using DIDSON. Fisheries Science 75: 1359-1367.

Hassell MP, May RM. 1974. Aggregation of Predators and Insect Parasites and Its Effect on Stability. Journal of Animal Ecology 43: 567-594.

Heithaus MR, Wirsing AJ, Burkholder D, Thomson J, Dill LM. 2009. Towards a Predictive Framework for Predator Risk Effects: The Interaction of Landscape Features and Prey Escape Tactics. Journal of Animal Ecology 78: 556-562.

Holmes JA, Cronkite GMW, Enzenhofer HJ, Mulligan TJ. 2006. Accuracy and Precision of Fish-Count Data from a "Dual-Frequency Identification Sonar" (DIDSON) Imaging System. Ices Journal of Marine Science 63: 543-555.

Hugie DM, Dill LM. 1994. Fish and Game: A Game Theoretic Approach to Habitat Selection by Predators and Prey. Journal of Fish Biology 45: 151-169.

Lancaster J. 1996. Scaling the Effects of Predation and Disturbance in a Patchy Environment. Oecologia 107: 321-331.

Lima SL. 2002. Putting Predators Back into Behavioral Predator-Prey Interactions. Trends in Ecology \& Evolution 17: 70-75.

Lima SL, Dill LM. 1990. Behavioral Decisions Made under the Risk of Predation: A Review and Prospectus. Canadian Journal of Zoology 68: 619-640.

Loftus WF. 2000. Accumulation and Fate of Mercury in an Everglades Aquatic Food Web. Ph.D. Dissertation. Florida International University, Miami.

Loftus WF, Kushlan JA. 1987. Freshwater Fishes of Southern Florida. Pages 147-344. Florida State Museum Biological Sciences.

Løkkeborg S, Fernö A. 1999. Diel Activity Pattern and Food Search Behaviour in Cod, Gadus morhua. Environmental Biology of Fishes 54: 345-353.

Lucas MC, Baras E. 2000. Methods for Studying Spatial Behaviour of Freshwater Fishes in the Natural Environment. Fish and Fisheries 1: 283-316. 
Magoulick DD, Kobza RM. 2003. The Role of Refugia for Fishes During Drought: A Review and Synthesis. Freshwater Biology 48: 1186-1198.

Maxwell SL, Gove NE. 2007. Assessing a Dual-Frequency Identification Sonars' FishCounting Accuracy, Precision, and Turbid River Range Capability. Journal of the Acoustical Society of America 122: 3364-3377.

McMahon T, Holanov S. 1995. Foraging Success of Largemouth Bass at Different Light Intensities: Implications for Time and Depth of Feeding. Journal of Fish Biology 46: 759-767.

Menge BA, Olson AM. 1990. Role of Scale and Environmental Factors in Regulation of Community Structure. Trends in Ecology \& Evolution 5: 52-57.

Moursund RA, Carlson TJ, Peters RD. 2003. A Fisheries Application of a DualFrequency Identification Sonar Acoustic Camera. Ices Journal of Marine Science 60: 678-683.

Muirhead J, Sprules WG. 2003. Reaction Distance of Bythotrephes longimanus, Encounter Rate and Index of Prey Risk for Harp Lake, Ontario. Freshwater Biology 48: 135-146.

Naud M, Magnan P. 1988. Diel Onshore-Offshore Migrations in Northern Redbelly Dace, Phoxinus eos (Cope), in Relation to Prey Distribution in a Small Oligotrophic Lake. Canadian Journal of Zoology 66: 1249-1253.

Newlands NK, Lutcavage ME, Pitcher TJ. 2004. Analysis of Foraging Movements of Atlantic Bluefin Tuna (Thunnus thynnus): Individuals Switch between Two Modes of Search Behaviour. Population Ecology 46: 39-53.

Parrish J. 1991. Do Predators 'Shape' Fish Schools: Interactions between Predators and Their Schooling Prey. Netherlands Journal of Zoology, 42 2: 358-370.

Pitcher TJ, Parrish JK. 1992. Functions of Shoaling Behavior in Teleosts. Pages 363-440 in Pitcher TJ, ed. The Behaviour of Teleost Fishes. Baltimore, MD: Johns Hopkins University Press.

Poff NL. 1997. Landscape Filters and Species Traits: Towards Mechanistic Understanding and Prediction in Stream Ecology. Journal of the North American Benthological Society 16: 391-409.

Preisser EL, Bolnick DI, Benard MF. 2005. Scared to Death? The Effects of Intimidation and Consumption in Predator-Prey Interactions. Ecology 86: 501-509.

Pyke GH, Pulliam HR, Charnov EL. 1977. Optimal Foraging: A Selective Review of Theory and Tests. The Quarterly Review of Biology 52: 137-154. 
Rehage JS, Trexler JC. 2006. Assessing the Net Effect of Anthropogenic Disturbance on Aquatic Communities in Wetlands: Community Structure Relative to Distance from Canals. Hydrobiologia 569: 359-373.

Rehage JS, Dunlop KL, Loftus WF. 2009. Antipredator Responses by Native Mosquitofish to Non-Native Cichlids: An Examination of the Role of Prey Naiveté. Ethology 115: 1046-1056.

Schlosser IJ. 1987. The Role of Predation in Age- and Size-Related Habitat Use by Stream Fishes. Ecology 68: 651-659.

Schowalter TD. 2012. Insect Responses to Major Landscape-Level Disturbance. Annual Review of Entomology 57: 1-20.

Sih A. 2005. Predator-Prey Space Use as an Emergent Outcome of a Behavioral Response Race in Barbosa P, Castellanos I, eds. Ecology of Predator-Prey Interaction, Oxford University Press.

Sih A, Englund G, Wooster D. 1998. Emergent Impacts of Multiple Predators on Prey. Trends in Ecology \& Evolution 13: 350-355.

Sousa WP. 1984. The Role of Disturbance in Natural Communities. Annual Review of Ecology and Systematics: 353-391.

Taylor PD, Fahrig L, Henein K, Merriam G. 1993. Connectivity Is a Vital Element of Landscape Structure. Oikos: 571-573.

Tiffan KF, Rondorf DW, Skalicky JJ. 2004. Imaging Fall Chinook Salmon Redds in the Columbia River with a Dual-Frequency Identification Sonar. North American Journal of Fisheries Management 24: 1421-1426.

Tiffan KF, Haskell CA, Kock TJ. 2010. Quantifying the Behavioral Response of Spawning Chum Salmon to Elevated Discharges from Bonneville Dam, Columbia River, USA. River Research and Applications 26: 87-101.

Trexler J, Loftus W, Perry S. 2005. Disturbance Frequency and Community Structure in a Twenty-Five Year Intervention Study. Oecologia 145: 140-152.

Trexler J, Loftus W, Jordan F, Chick J, Kandl K, McElroy T, Bass O. 2001. Ecological Scale and Its Implications for Freshwater Fishes in the Florida Everglades. Pages 153-181 in Porter JW, Porter KG, eds. The Everglades, Florida Bay, and Coral Reefs of the Florida Keys: An Ecosystem Sourcebook. Boca Raton, FL: CRC Press.

Trexler JC, Goss CW. 2009. Aquatic Fauna as Indicators for Everglades Restoration: Applying Dynamic Targets in Assessments. Ecological Indicators 9: S108-S119. 
Turesson H, Brönmark C. 2007. Predator-Prey Encounter Rates in Freshwater Piscivores: Effects of Prey Density and Water Transparency. Oecologia 153: 281290.

Turner MG. 1989. Landscape Ecology: The Effect of Pattern on Process. Annual Review of Ecology and Systematics 20: 171-197.

Valeix M, Fritz H, Loveridge A, Davidson Z, Hunt J, Murindagomo F, Macdonald D. 2009. Does the Risk of Encountering Lions Influence African Herbivore Behaviour at Waterholes? Behavioral Ecology and Sociobiology 63: 1483-1494.

Verdolin JL. 2006. Meta-Analysis of Foraging and Predation Risk Trade-Offs in Terrestrial Systems. Behavioral Ecology and Sociobiology 60: 457-464.

Welborn GA, Skelly DK, Werner EE. 1996. Mechanisms Creating Community Structure across a Freshwater Habitat Gradient. Annual Review of Ecology and Systematics 27: $337-363$.

Werner E, Gilliam J, Hall D, Mittelbach G. 1983. An Experimental Test of the Effects of Predation Risk on Habitat Use in Fish. Ecology 64: 1540-1548. 
Table 1. Date of sampling events for the seasonal and diel studies. Window length (5 or $10 \mathrm{~m}$ ) used to collect acoustic data is listed under each canal sampling event. Samples not collected are indicated by '-'.

\begin{tabular}{ccccccccc}
\hline & \multicolumn{3}{c}{ Season } & \multicolumn{2}{c}{ Canal } & \multicolumn{2}{c}{ L67C } & \multicolumn{2}{c}{ L31W } & \multicolumn{2}{c}{ C111 } \\
& \multirow{2}{*}{ Study } & Category & Day & Night & Day & Night & Day & Night \\
\hline $12-2010$ & Seasonal & & 10 & - & 10 & - & - & - \\
$1-2011$ & Seasonal & Early Dry & 10 & - & 10 & - & - & - \\
$2-2011$ & Seasonal & Early Dry & 10 & - & 10 & - & - & - \\
$3-2011$ & Seasonal & Early Dry & 10 & - & 10 & - & - & - \\
$4-2011$ & Seasonal & Dry & 10 & - & 5 & - & - & - \\
$5-2011$ & Seasonal & Dry & 5 & - & 5 & - & - & - \\
$6-2011$ & Seasonal & Dry & 5 & - & 5 & - & - & - \\
$7-2011$ & Seasonal & Wet & - & - & - & - & - & - \\
$8-2011$ & Seasonal & Wet & 5 & - & 5 & - & - & - \\
$9-2011$ & Seasonal & Wet & 5 & - & 5 & - & - & - \\
$10-2011$ & Seasonal & Wet & 5 & - & 5 & - & - & - \\
$2-2012$ & Diel & & 10 & 10 & 10 & 10 & 10 & 10 \\
$3-2012$ & Diel & & 10 & - & 10 & 10 & - & - \\
$4-2012$ & Diel & & 10 & 10 & 10 & 10 & 10 & 10 \\
$5-2012$ & Diel & & 10 & 10 & 10 & 10 & 10 & 10 \\
\hline
\end{tabular}


Table 2. Results from nested ANCOVA for small- and large-fish densities.

\begin{tabular}{lcccccc}
\hline \multirow{2}{*}{ Effect } & \multicolumn{3}{c}{ Small Fish } & \multicolumn{3}{c}{ Large Fish } \\
& df & $F$ & $p$ & df & $F$ & $p$ \\
\hline Season & 2,44 & 1.85 & 0.17 & 2,46 & 2.21 & 0.12 \\
Canal & 1,44 & 0.05 & 0.83 & 1,46 & 0.77 & 0.38 \\
Season * Canal & 2,44 & 4.32 & 0.02 & 2,46 & 11.20 & $<0.001$ \\
Water Level(Canal) & 2,44 & 0.10 & 0.90 & 2,46 & 7.26 & 0.002 \\
Large Fish(Canal) & 2,44 & 2.93 & 0.06 & - & - & - \\
\hline
\end{tabular}


Table 3. Model fit statistics from the five best models for predicting the probability of detecting a school as a function of canal, large-fish density (LF), small-fish density (SF), or days of connectivity, and their combinations.

\begin{tabular}{lccc}
\hline \multicolumn{1}{c}{ Model } & $\Delta \mathrm{AICc}$ & $\mathrm{R}^{2}$ & Evidence Ratios \\
\hline $\mathrm{LF}+\mathrm{SF}$ & 0 & 0.92 & 1 \\
$\mathrm{SF}$ & 0.26 & 0.92 & 1.1 \\
$\mathrm{SF}($ Canal $)$ & 0.91 & 0.92 & 1.6 \\
SF Canal & 1.23 & 0.92 & 1.8 \\
$\mathrm{LF}($ Canal $)+$ SF(Canal) & 1.35 & 0.93 & 2.0 \\
\hline
\end{tabular}


Table 4. Model fit statistics from the five best models for predicting nearest-neighbor distance and distance to school's centroid as a function of canal, season, large-fish density (LF), small-fish density (SF), or marsh water-depth (MWD), and their combinations.

\begin{tabular}{lccc}
\hline \multicolumn{1}{c}{ Model } & $\Delta$ AICc & $\mathrm{R}^{2}$ & Evidence Ratios \\
\hline & Nearest-Neighbor Distance & \\
Canal + LF + SF & 0 & 0.74 & 1 \\
LF(Canal) + SF(Canal) & 1.9 & 0.75 & 2.6 \\
LF + SF & 3.6 & 0.68 & 6 \\
LF + SF + MWD & 5.8 & 0.69 & 18.2 \\
Canal + LF + SF + Season & 6.7 & 0.74 & 28.5 \\
\multicolumn{4}{l}{ Season } \\
Season + SF & Distance to Centroid & \\
Season + Canal & \multicolumn{4}{c}{0.34} & 1 \\
Season + LF & 1.9 & 0.36 & 2.6 \\
Season + MWD & 2.4 & 0.35 & 3.3 \\
\hline
\end{tabular}


Table 5. Results from ANOVA for small- and large-fish densities.

\begin{tabular}{lcccccc}
\hline \multirow{2}{*}{ Effect } & \multicolumn{3}{c}{ Small Fish } & \multicolumn{3}{c}{ Large Fish } \\
& df & $F$ & $p$ & df & $F$ & $p$ \\
\hline Month & 2,53 & 9.05 & $<0.001$ & 2 & 8.09 & $<0.001$ \\
Canal & 2,50 & 5.10 & 0.012 & 2 & 4.29 & 0.017 \\
Time of Day(Canal) & 3,30 & 2.87 & 0.053 & 3 & 3.36 & 0.023 \\
Month * Time of Day(Canal) & 10,53 & 3.31 & 0.002 & 10 & 3.47 & $<0.001$ \\
\hline
\end{tabular}




\section{FIGURE CAPTIONS}

Figure 1. Map of study sites within Florida Everglades, USA. The L67C is located in the Gap between Water Conservation 3A and 3B and the L31W and C111 canals are located adjacent to Everglades National Park.

Figure 2. Mean marsh water-depth adjacent to the $\mathrm{L} 31 \mathrm{~W}$ and $\mathrm{L} 67 \mathrm{C}$ canals from November 1, 2010 - November 1, 2011. Water levels $<15 \mathrm{~cm}$ and $<5 \mathrm{~cm}$ are not accessable by large and small fish, respectively. Seasons were defined as early dry (Jan. - Mar. 2011), dry (Apr. - Jun. 2011), and wet (Aug. - Oct. 2011).

Figure 3. Observed large-fish density in the (A) L67C and (B) L31W canals regressed against marsh water-depths pooled across seasons. Solid black lines are predicted values. (C) Least squared means ( \pm standard error) of large-fish densities for each canal and season. Letters above bars indicate pair-wise differences among means. Means are significantly different $(p<0.05)$ if there are no letters in common. Densities in all panels are plotted on square-root transformed scale.

Figure 4. Partial regression plots for residuals of natural-log transformed small-fish density and residuals of large-fish density in (A) L67C and (B) L31W canals. Plots remove the effect of the remaining independent variables to illustrate the actual model fit for each independent variable. Residuals were obtained from separate regressions of small- and large-fish densities on marsh water-depth and season for each canal.

Figure 5. Probability of detecting a school as a function of small-fish density.

Figure 6. Partial regression plots for residuals of natural-log transformed nearestneighbor distance and residuals of natural-log transformed small-fish density in the (A) L67C and (B) L31W canals, and residuals of square-root transformed large-fish density in the (C) L67C and (D) L31W canals. Plots partial out the effect of remaining independent variables.

Figure 7. Least squared means ( \pm standard error) of distance to school's centroid for the early dry, dry, and wet seasons. Distance is plotted on natural-log transformed scale.

Figure 8. Mean marsh water-depth adjacent to the C111, L31W, and L67C canals from January 1 - June 1, 2012. Arrows indicate sampling dates. Water levels $<15 \mathrm{~cm}$ and $<5$ $\mathrm{cm}$ are not accessable by large and small fish, respectively.

Figure 9. Least squared means ( \pm standard error) of small-fish density for the (A) L31W, (B) L67C, and (C) C111 canals from February - May 2012. Asterisks indicate day and night mean densities are significantly different for that month $(p<0.05)$. Densities are plotted on natural-log transformed scale. 
Figure 10. Least squared means ( \pm standard error) of large-fish density for the (A) L31W, (B) L67C, and (C) C111 canals from February - May 2012. Asterisks indicate day and night mean densities are significantly different for that month $(\mathrm{p}<0.05)$. Densities are plotted on natural-log transformed scale.

Figure 11. Frequency distribution of swimming speeds for (A) L67C small fish, (B) L67C large fish, (C) L31W small fish, (D) L31W large fish, (E) C111 small fish, and (F) C111 large fish.

Figure 12. Least squared means ( \pm standard error) of (A) small- and (B) large-fish swimming speeds. Asterisks indicate day and night mean densities are significantly different for that month $(\mathrm{p}<0.05)$. Densities are plotted on natural-log transformed scale.

Figure 13. Total encounter rate (no. predators and prey $\mathrm{m}^{-3} \mathrm{~h}^{-1}$ ) by time of day and month in the (A) C111, (B) L31W, and (C) L67C Canals. Daytime encounter rates were calculated with two measures of prey density: all prey and schools treated as one fish. 
Figure 1.

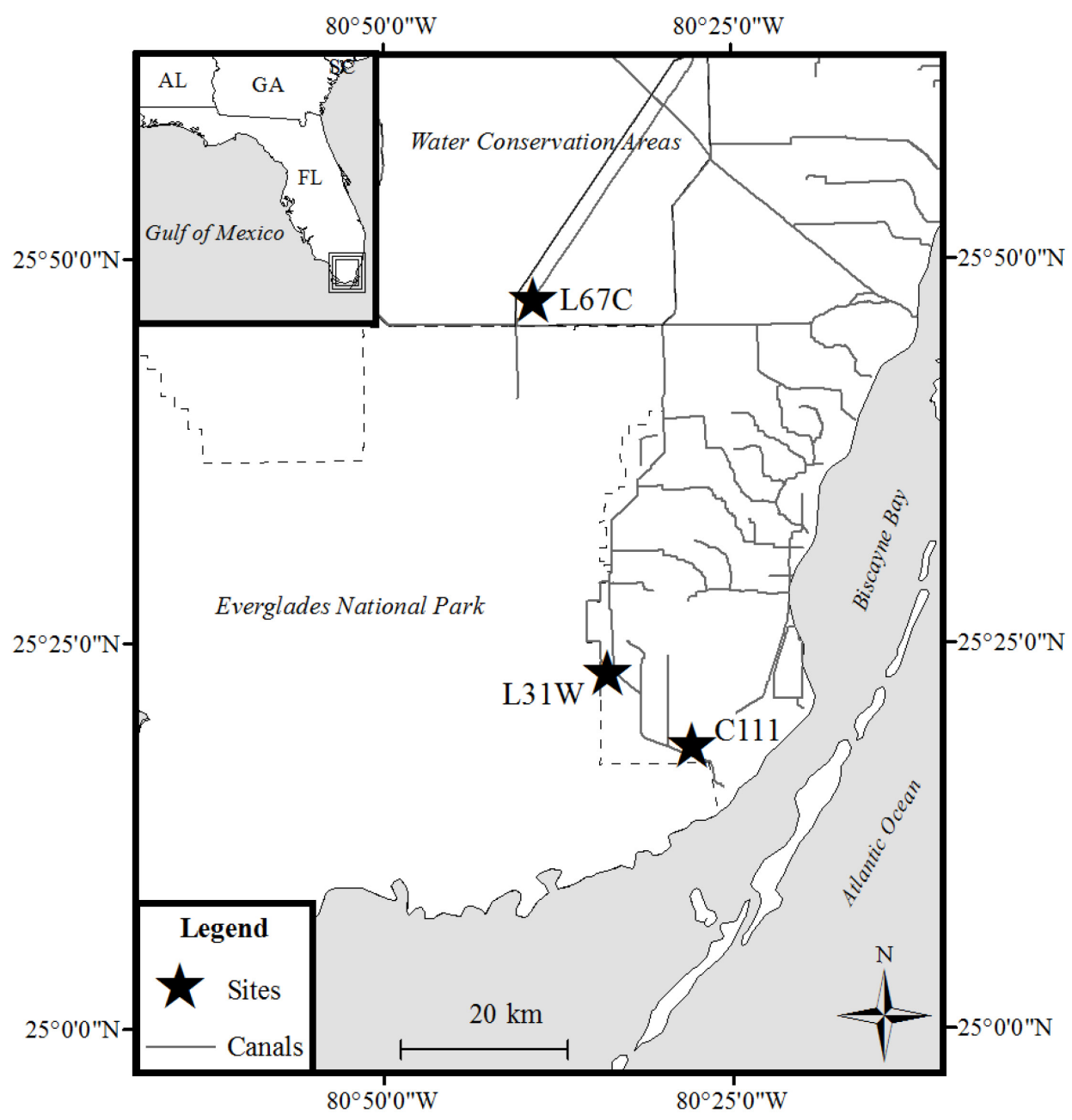


Figure 2.

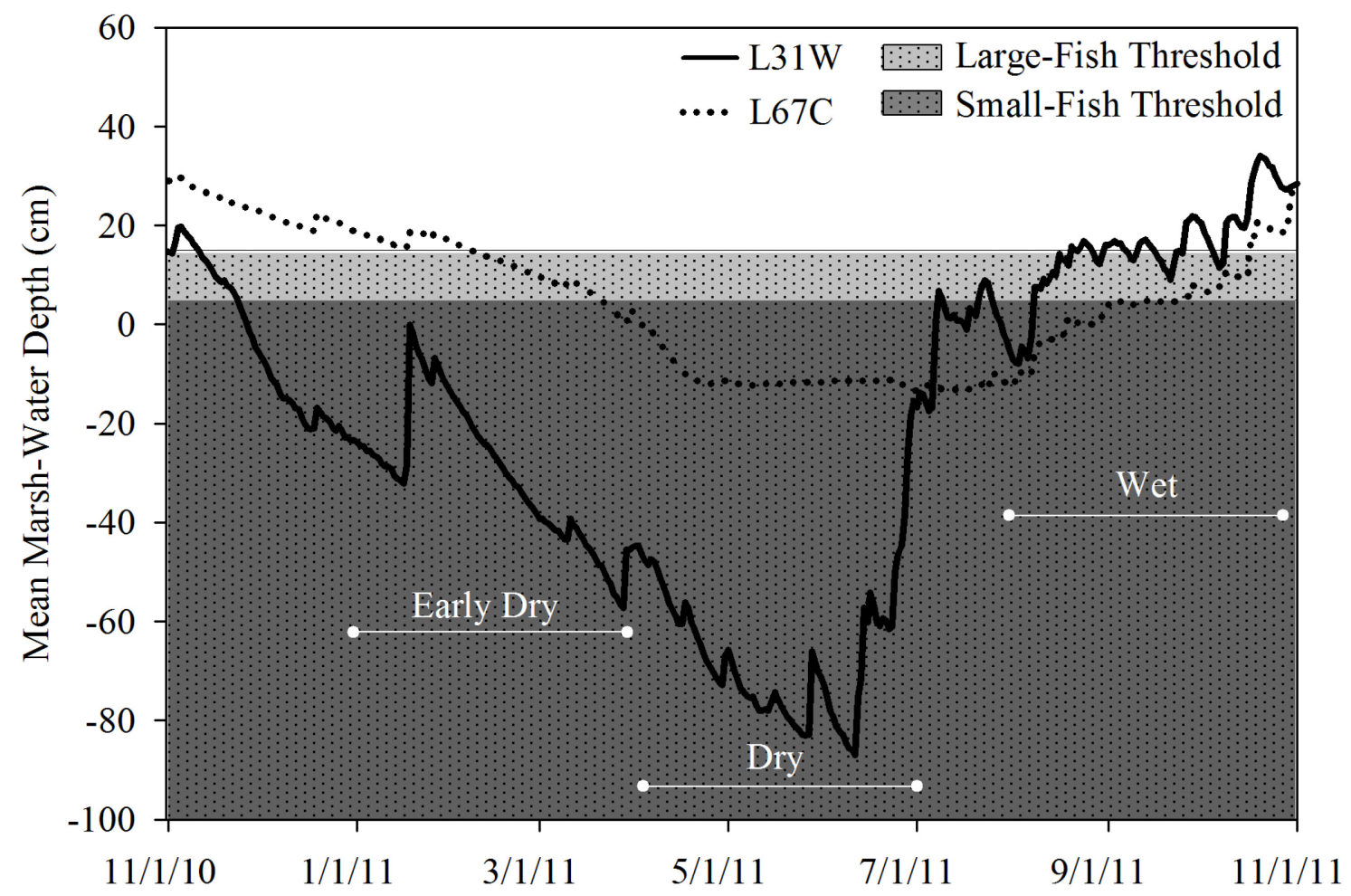


Figure 3.

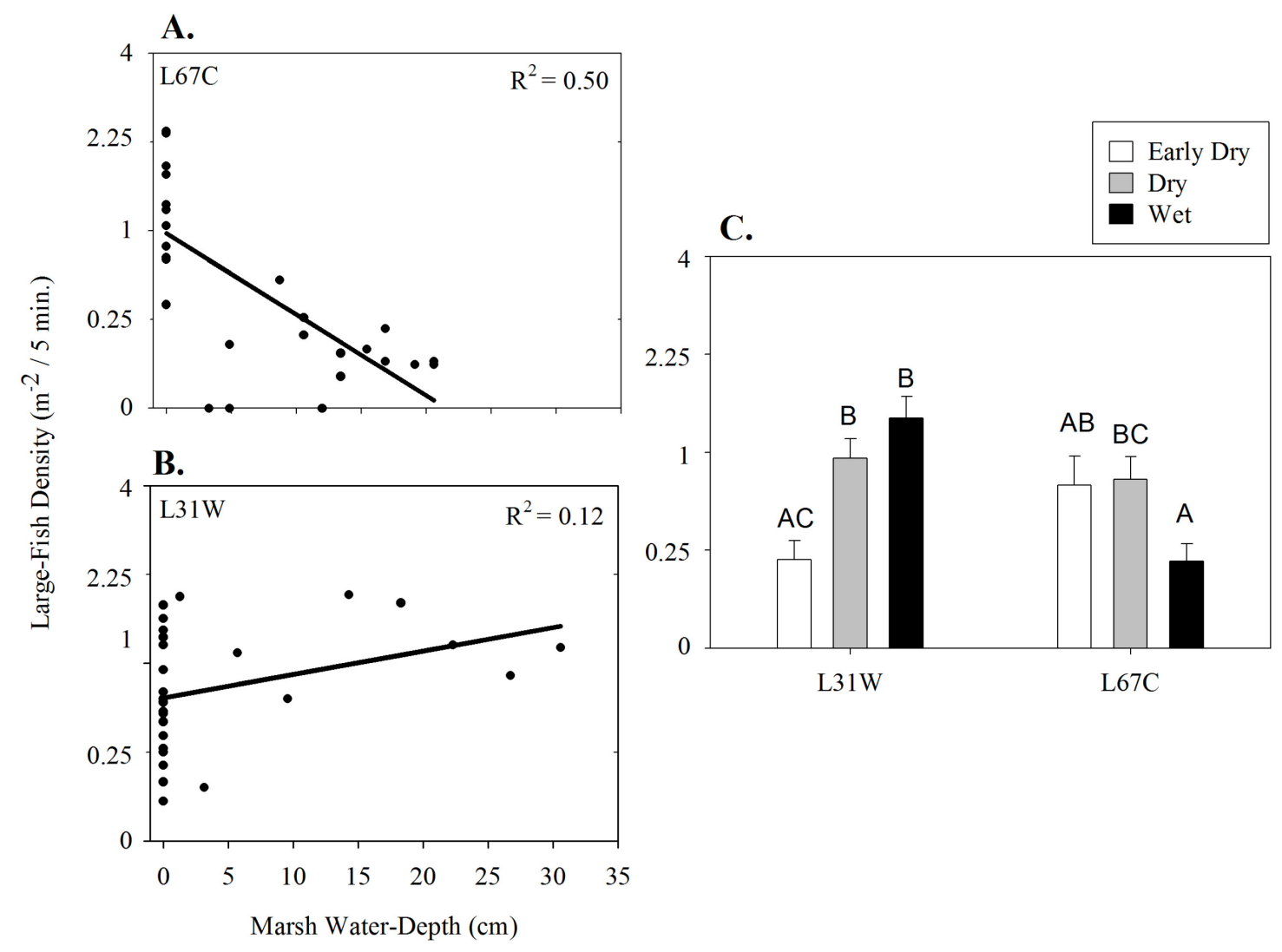


Figure 4.

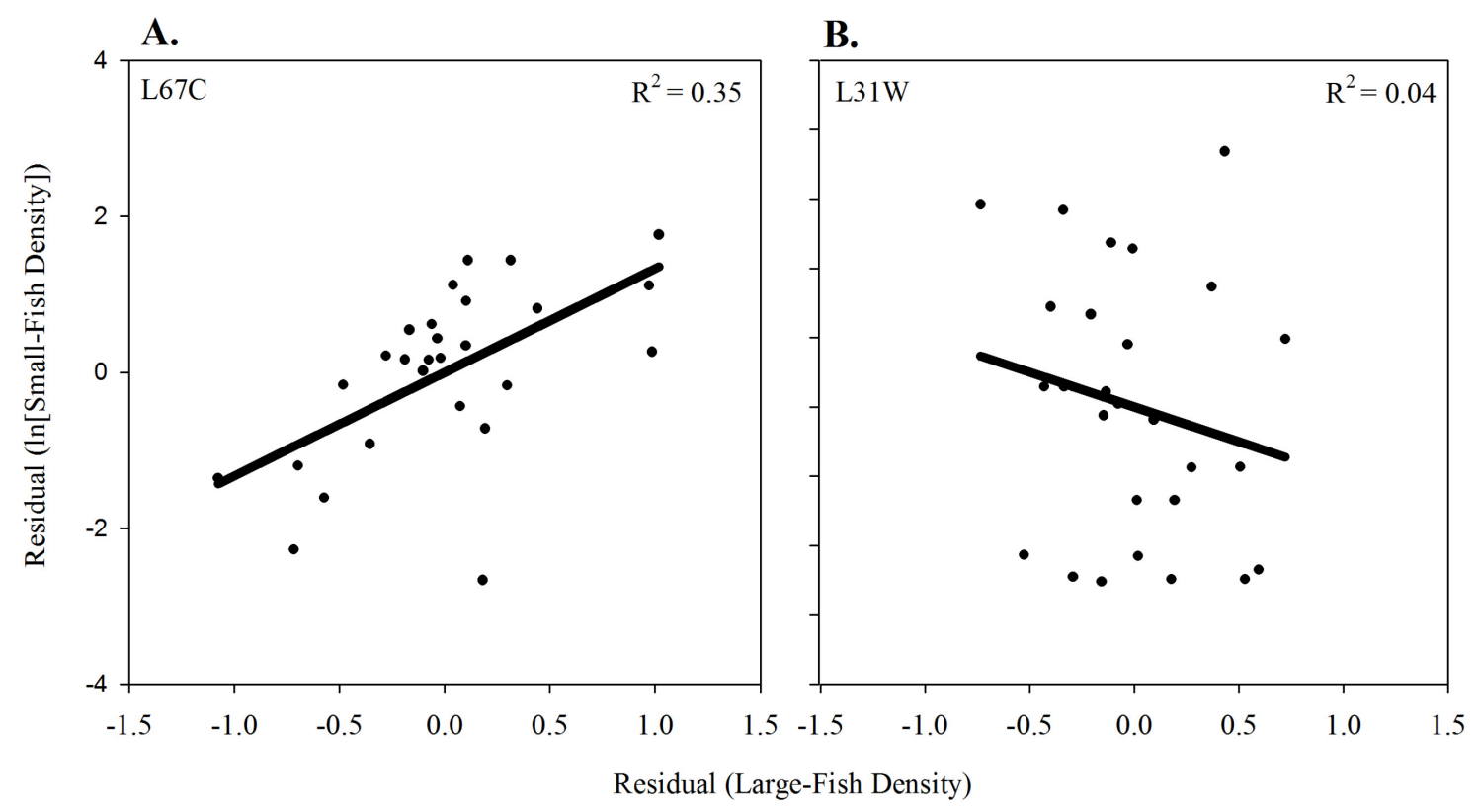


Figure 5.

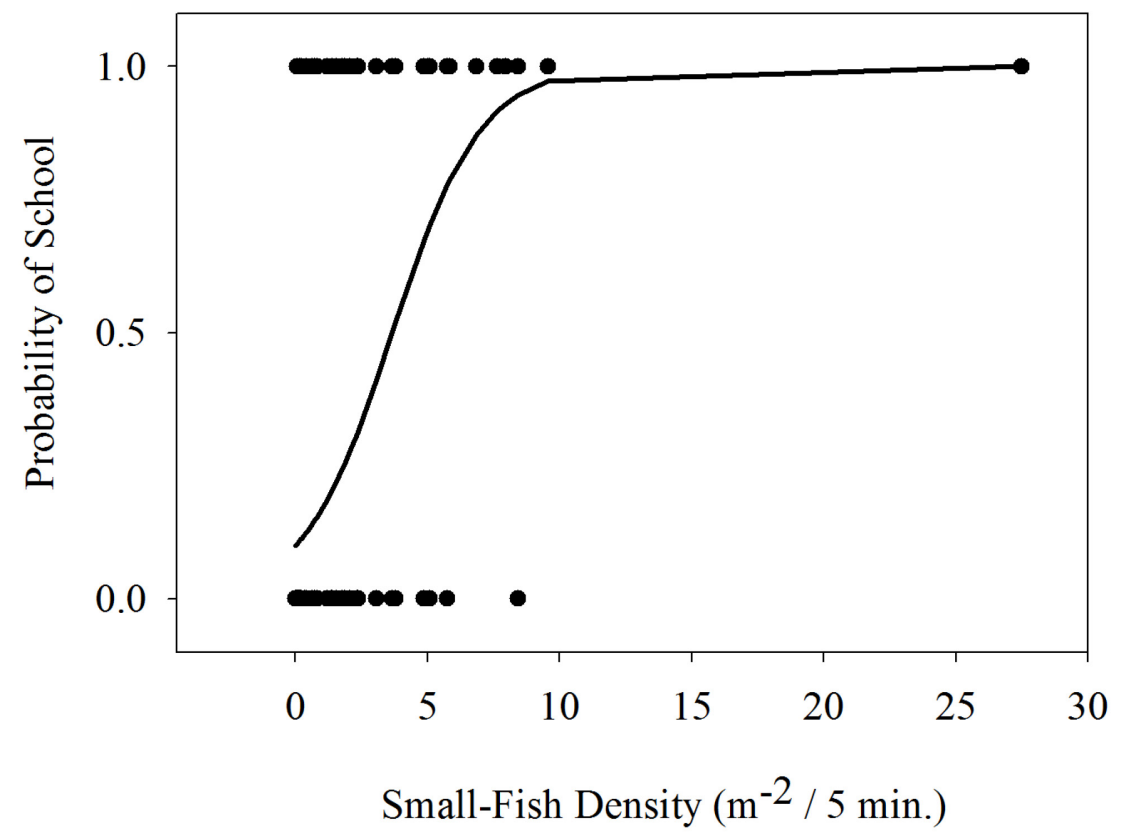


Figure 6.
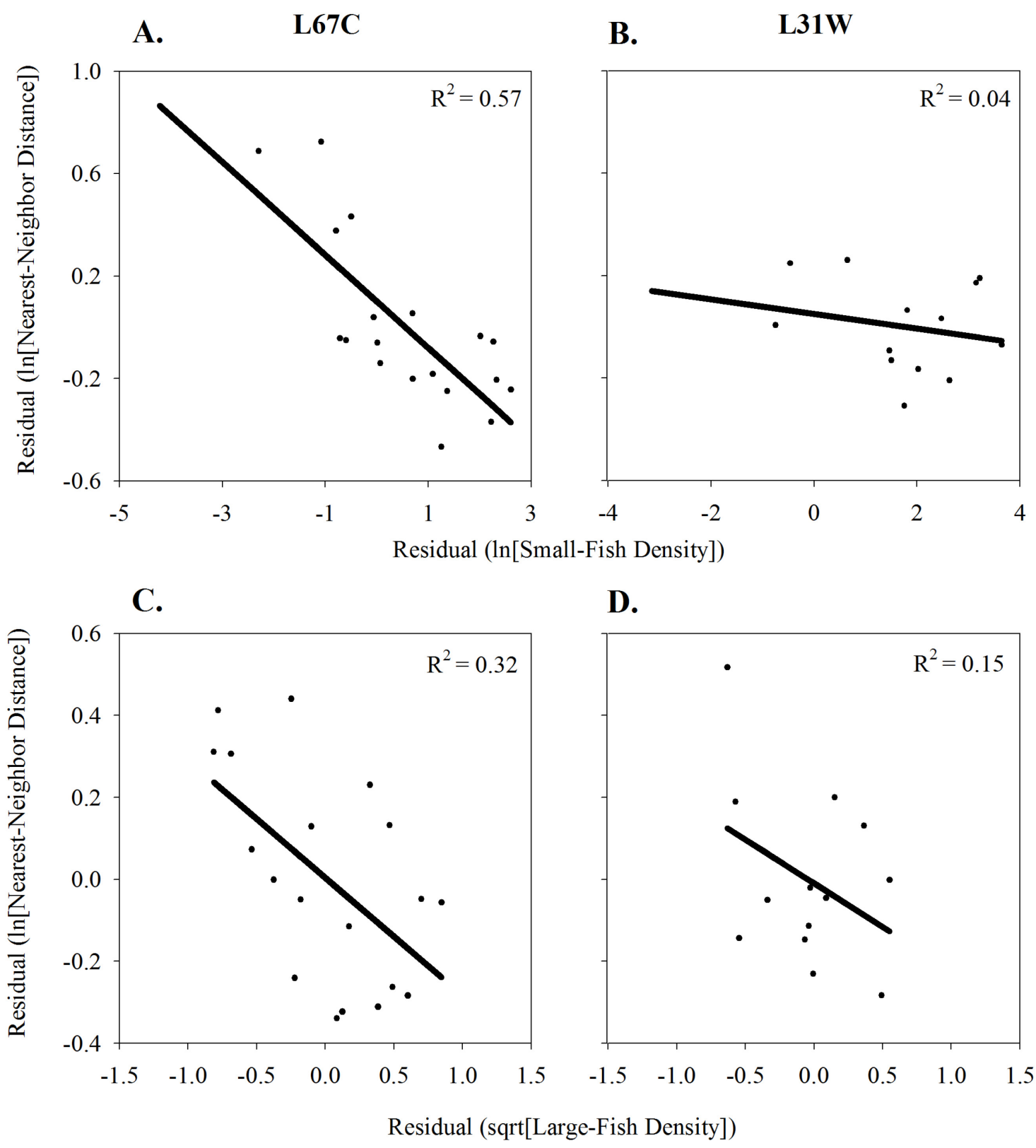
Figure 7.

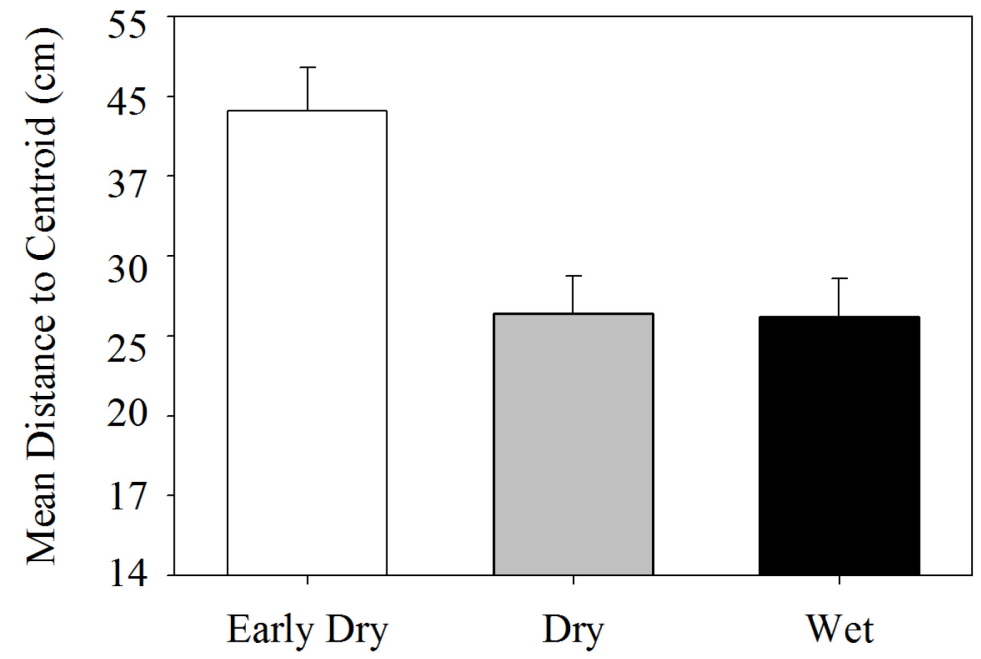


Figure 8.

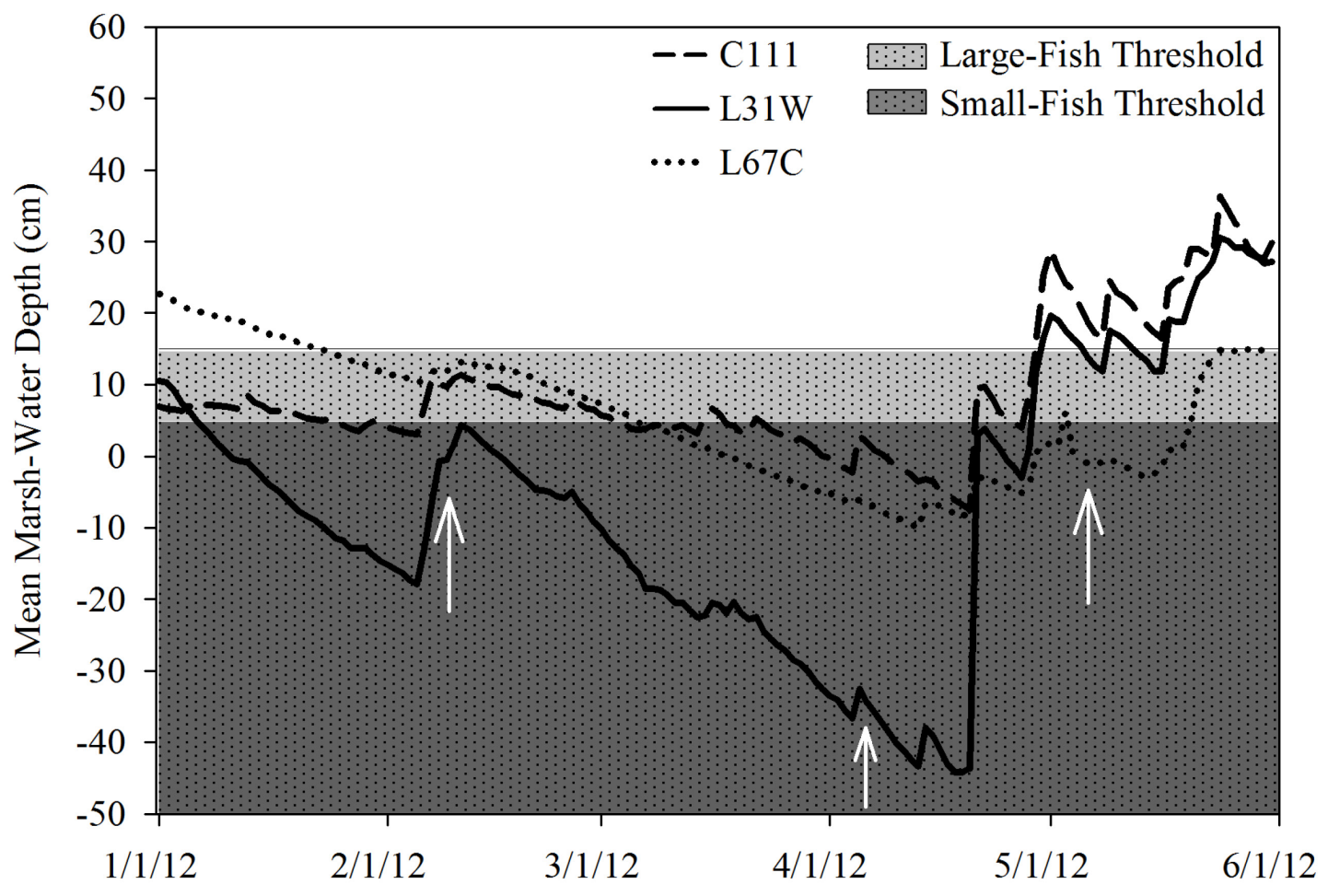


Figure 9.

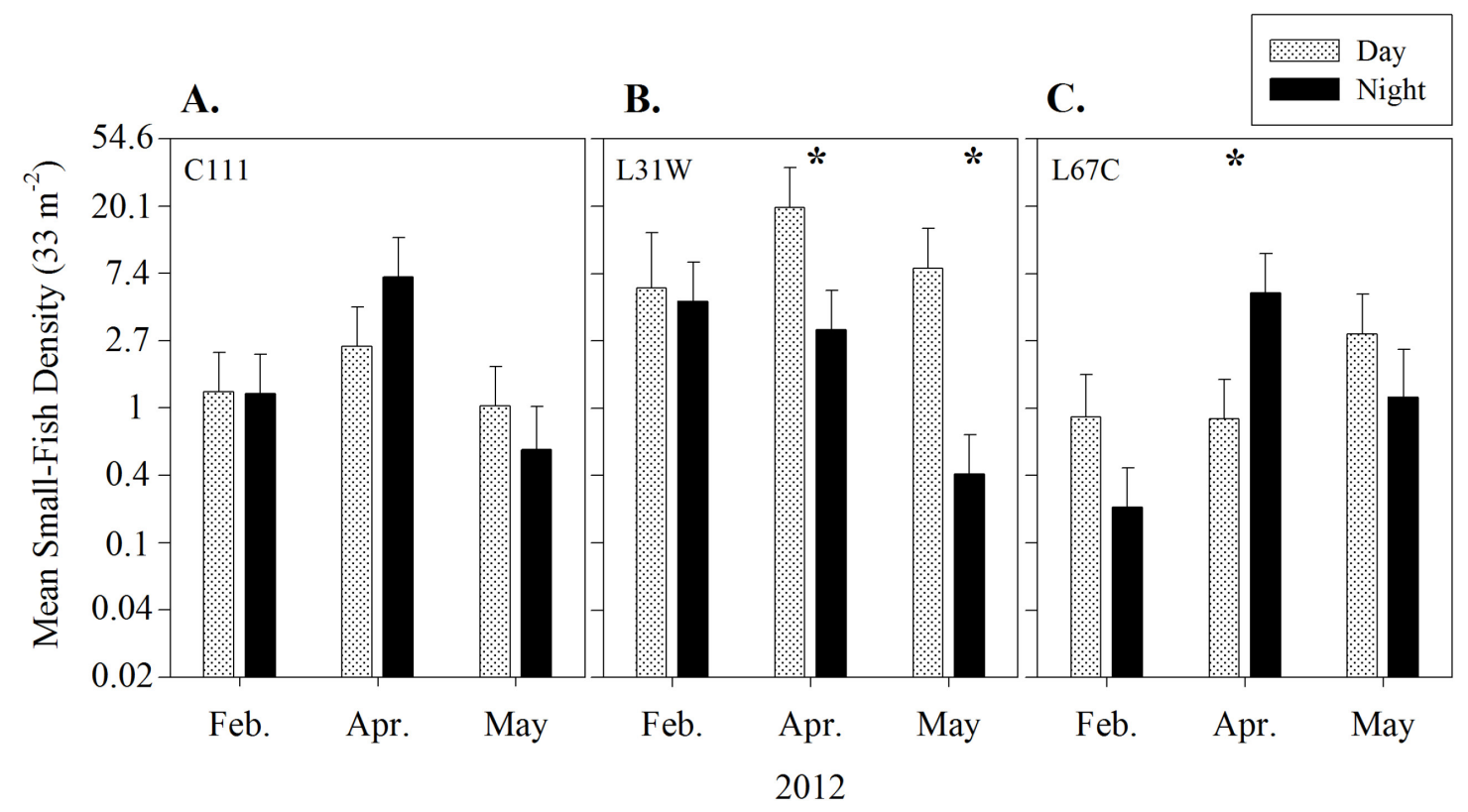


Figure 10.

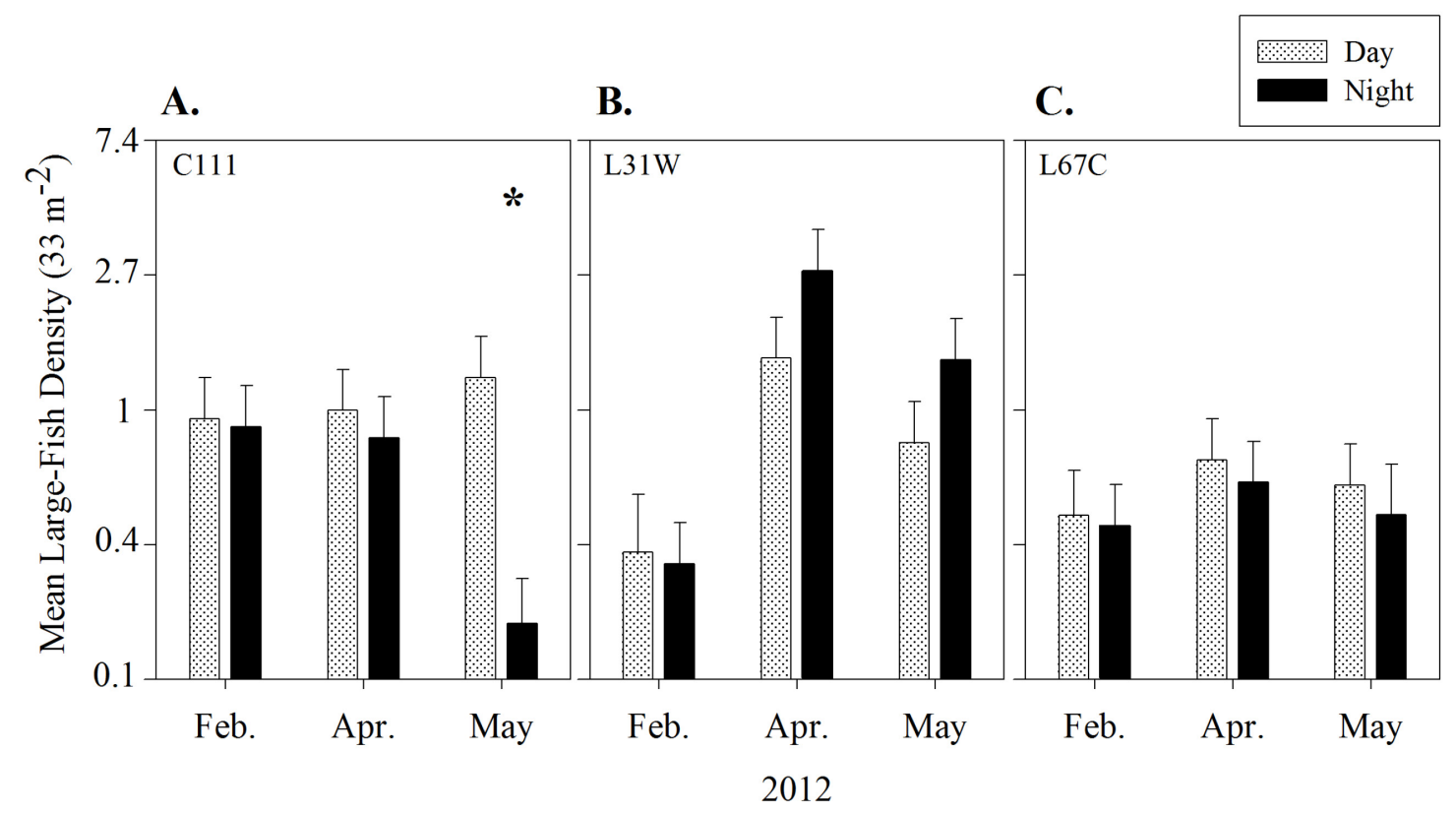


Figure 11.
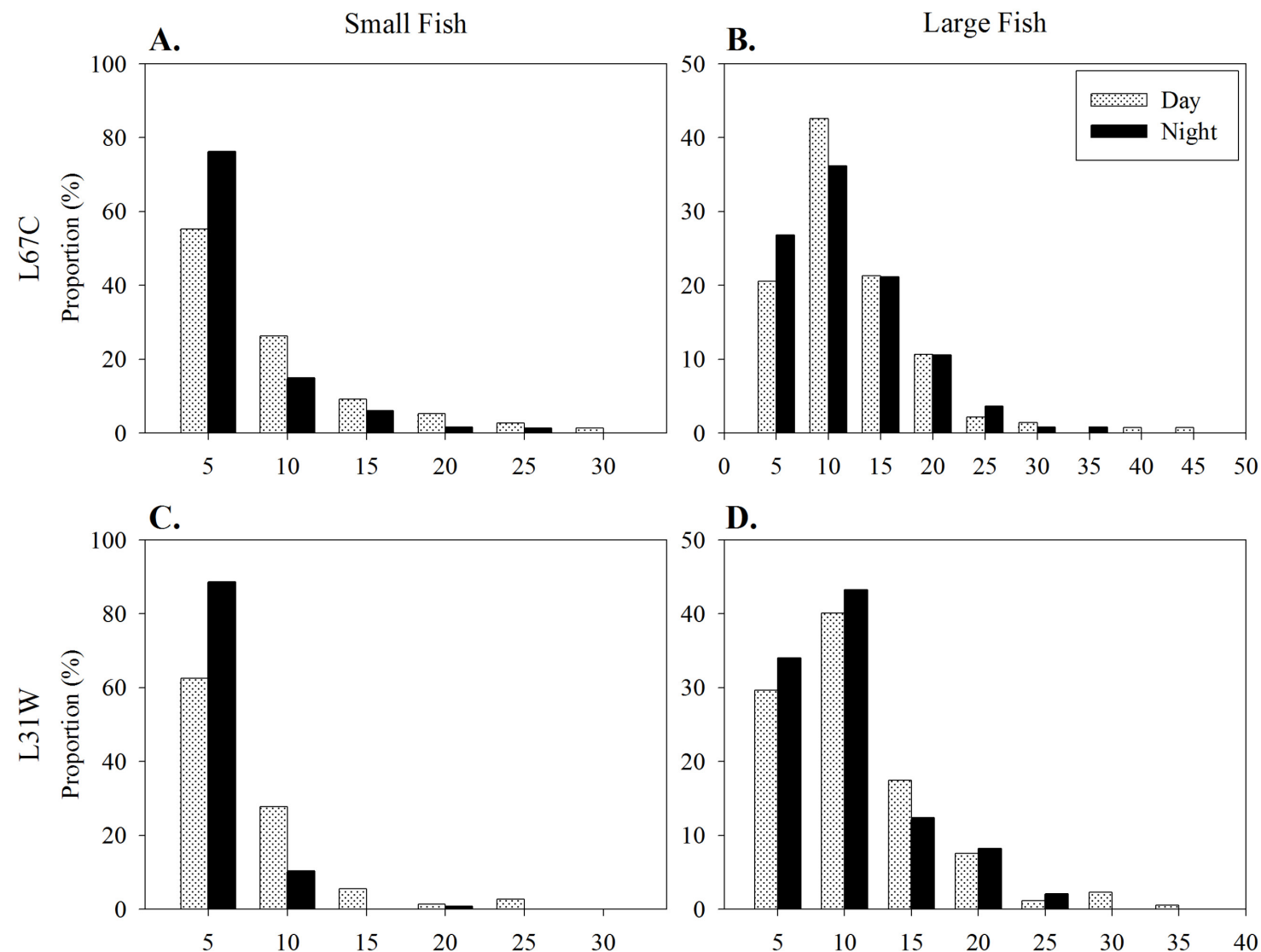

D.
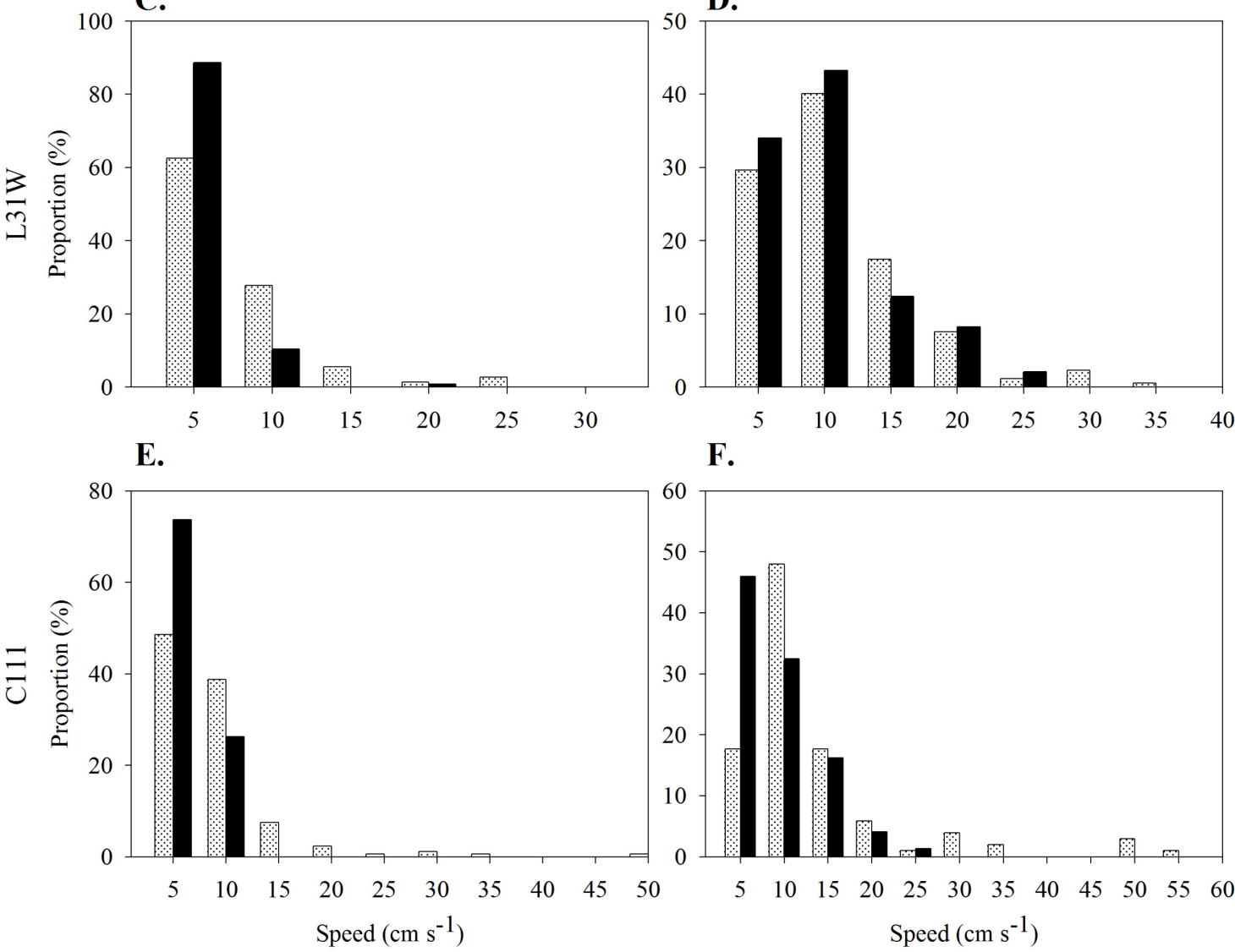

F.

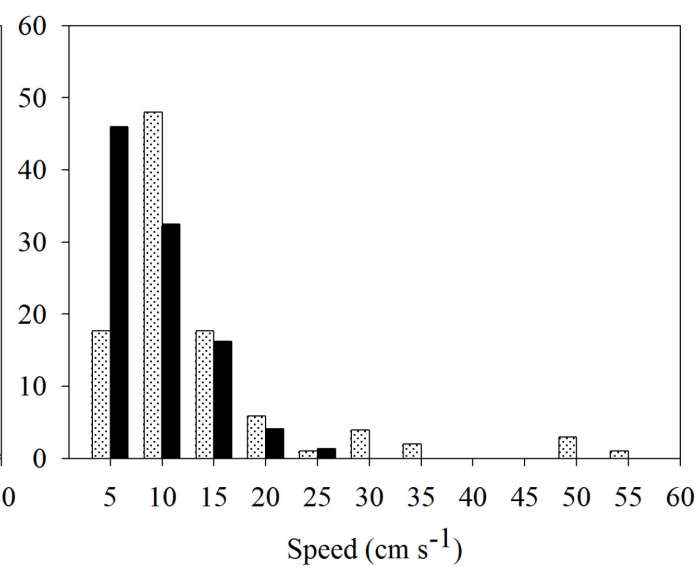


Figure 12.
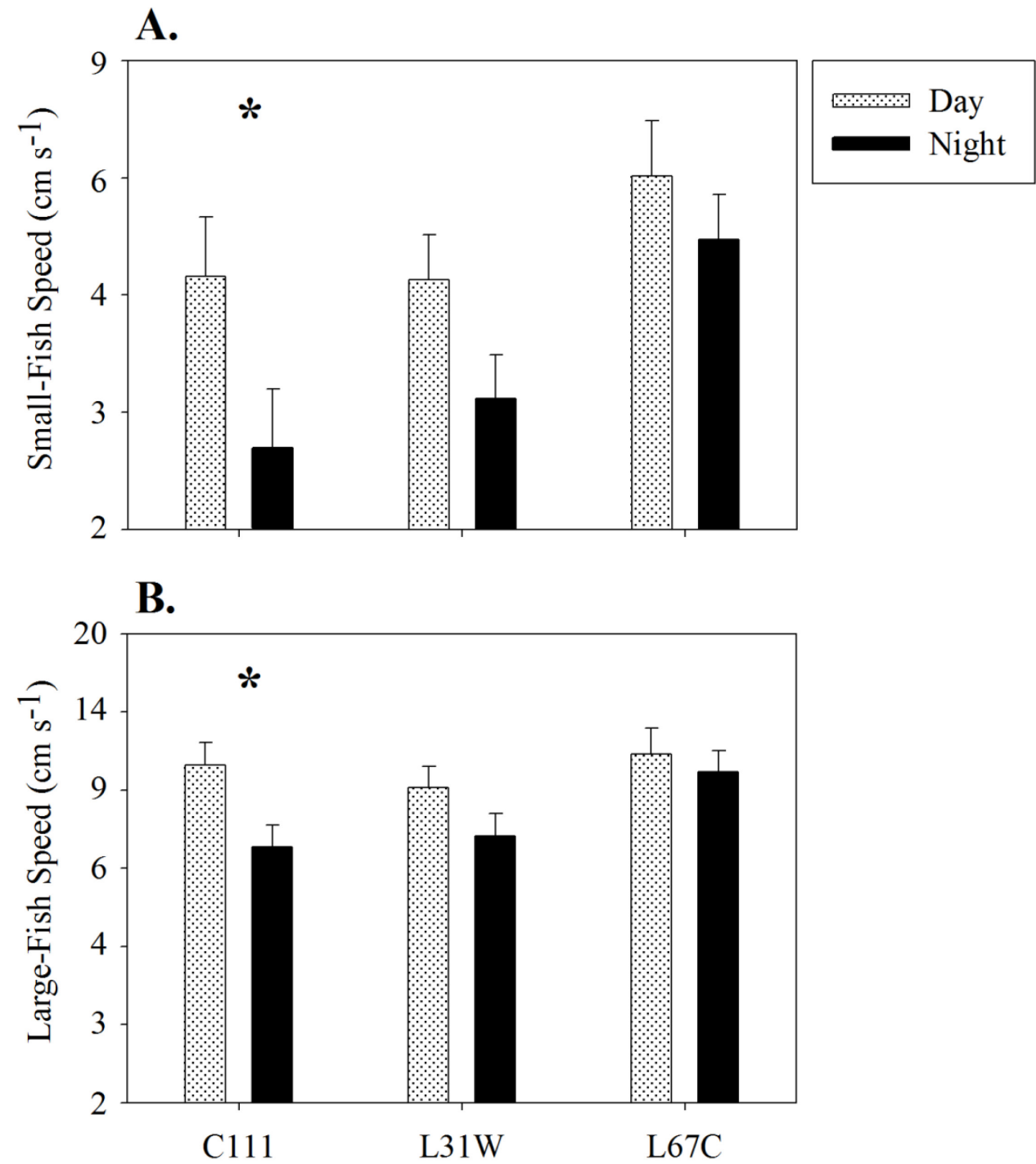
Figure 13.

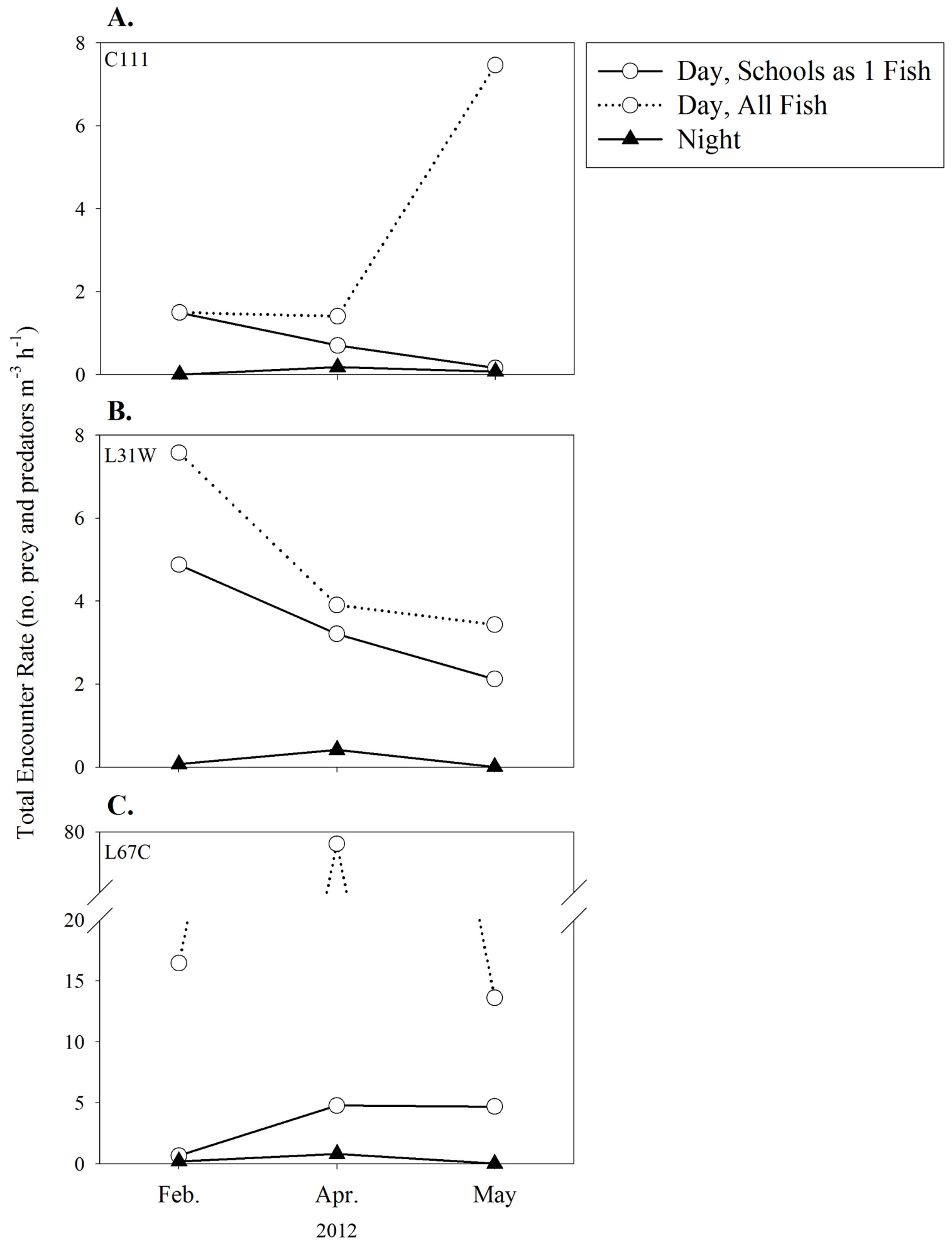

